DYNAMIC RESPONSE OF SINGLE CRYSTALLINE COPPER SUBJECTED TO QUASI-ISENTROPIC, GAS-GUN DRIVEN LOADING

H. Jarmakani, J. M. Mc Naney, M. S. Schneider, B. Y. Cao, D. Orlikowski, J. H. Nguyen, B. Kad, M. A. Meyers

November 8, 2005 
This document was prepared as an account of work sponsored by an agency of the United States Government. Neither the United States Government nor the University of California nor any of their employees, makes any warranty, express or implied, or assumes any legal liability or responsibility for the accuracy, completeness, or usefulness of any information, apparatus, product, or process disclosed, or represents that its use would not infringe privately owned rights. Reference herein to any specific commercial product, process, or service by trade name, trademark, manufacturer, or otherwise, does not necessarily constitute or imply its endorsement, recommendation, or favoring by the United States Government or the University of California. The views and opinions of authors expressed herein do not necessarily state or reflect those of the United States Government or the University of California, and shall not be used for advertising or product endorsement purposes.

This work was performed under the auspices of the U.S. Department of Energy by University of California, Lawrence Livermore National Laboratory under Contract W-7405-Eng-48. 


\title{
DYNAMIC RESPONSE OF SINGLE CRYSTALLINE COPPER SUBJECTED TO QUASI-ISENTROPIC, GAS-GUN DRIVEN LOADING
}

\author{
H. Jarmakani ${ }^{1}$, J. M. Mc Naney ${ }^{2}$, M. S. Schneider ${ }^{1}$, B. Y. Cao ${ }^{1}$, D. Orlikowski ${ }^{2}$, J. H. \\ Nguyen $^{2}$, B. $\operatorname{Kad}^{1}$, M. A. Meyers ${ }^{1}$. \\ ${ }^{1}$ Mechanical and Aerospace Engineering Dept, Materials Science Program, University of California, San \\ Diego, La Jolla CA 920930418 \\ ${ }^{2}$ Lawrence Livermore National Laboratory, Livermore CA 94550
}

\begin{abstract}
A transmission electron microscopy study of quasi-isentropic gas-gun loading (peak pressures between $18 \mathrm{GPa}$ and $52 \mathrm{GPa}$ ) of [001] monocrystalline copper was carried out. The defect substructures at these different pressures were analyzed. Current experimental evidence suggests a deformation substructure that transitions from slip to twinning, where twinning occurs at the higher pressures ( $\sim 52 \mathrm{GPa})$, and heavily dislocated laths and dislocation cells take place at the intermediate and lower pressures. Evidence of stacking faults at the intermediate pressures was also found. Dislocation cell sizes decreased with increasing pressure and increased with distance away from the surface of impact. The results from the quasi-isentropic experiments are compared with that of flyer-plate and laser shock experiments carried out by Cao et al. [1] and Schneider et al. [2], respectively. The PrestonTonks-Wallace and Zerilli-Armstrong constitutive descriptions are used to model both isentropic and shock compression experiments and predict the pressure at which the sliptwinning transition occurs in both cases. Both models predict a higher transition for isentropic then for shock experiments, and indeed, that twinning should not take place in the ICE experiments at the pressures investigated.
\end{abstract}




\subsection{INTRODUCTION}

The response of copper to very high strain-rate deformation is reasonably well understood. In particular, shock experiments on copper have been carried out for over 50 years. Techniques using explosives and flyer plates were first employed to create the compressive pulse in the material, and pressures attained were on the order of tens of GPa with accompanying strain rates on the order of $10^{4} / \mathrm{sec}$ with durations on the order of microseconds or fractions thereof. More recently, laser pulses have been used to study shock compression in copper. The rapid heating and thermal expansion of the surface layers causes a shock to propagate through the material. Shock pressures higher than planar impact set-ups can be achieved (up to 75,000 GPa), and the strain rates attained are as high as $10^{9}-10^{11} 1 / \mathrm{sec}$. A basic difference is that the duration of the pulse in lasershock is on the order of nanoseconds rather than microseconds.

In this work, however, quasi-isentropic compression experiments (ICE), are carried out on [001] copper, and the recovered deformation substructure is analyzed. ICE is a shockless process where very high pressure conditions can be accessed, and the accompanying temperature rise is much less severe than in shock. The main motivation behind such a process is that the solid state of a material can be retained due to the lower temperatures experienced, and an understanding and characterization of the material response is, therefore, possible. In fact, quasi-isentropic experiments come very close to simulating conditions that occur in the depths of planets [3]. Entropy, the measure of the randomness of a system, does not change with depth in planets. Only temperature and pressure changes are experienced. ICE experiments in the early seventies were aimed at mimicking these conditions.

Quasi-isentropic compression conditions can be achieved by various methods: gas-gun, laser, and magnetic loading. In our case, gas-gun loading is used. Early work on ICE with gas-gun by Lyzenga et al. [4] used a composite flyer plate with materials of increasing shock impedance away from the target material. Barker [5] placed powders of varying densities along a powder blanket and pressed the blanket to produce a pillow impactor having a smooth shock impedance profile. Similarly, this current effort uses density graded impactors. 
In the case of ICE via laser, McNaney et al. [6] used a shockless laser drive setup to compress and recover an Al alloy. A smoothly rising pressure pulse is generated by focusing a laser beam on a reservoir material (carbon foam), creating a plasma that "stretches out" through a vacuum and discharges onto the sample. In the case of magnetically driven experiments [7], the Z accelerator at Sandia National Labs (SNL) is capable of producing quasi-isentropic compression loading of solids using magnetic pulses. An advantage of this method is that a smoothly rising pressure profile can be generated without the initial spike at low pressures seen during impact experiments. Control over loading pressures and a rise time is also possible to meet experimental requirements [7].

\subsection{EXPERIMENTAL PROCEDURE}

\subsection{ICE Set-up}

The two-stage gas gun and experimental set up for this work are located at LLNL. Functionally-graded material (FGM) impactors designed with increasing density profile (or shock impedance), as depicted in Fig. 1, were used to produce the smoothly rising pressure profiles [8]. Three different FGMs were used, each providing a certain density range. The first FGMs providing densities between $1.2 \mathrm{~g} / \mathrm{cc}$ to $8 \mathrm{~g} / \mathrm{cc}$ consisted of aluminum and tungsten powders in a resin matrix. The second FGMs allowing for very low densities up to $0.013 \mathrm{~g} / \mathrm{cc}$ consisted of a foam matrix having a density ranging between $0.1 \mathrm{~g} / \mathrm{cc}$ to $2.7 \mathrm{~g} / \mathrm{cc}$, and the third allowing for a higher density range between $2.7 \mathrm{~g} / \mathrm{cc}$ and $15 \mathrm{~g} / \mathrm{cc}$ consisted of sintered aluminum and tungsten powders. The density is varied by simply adding these premixed layers, each having a thickness of $200 \pm 20 \mu \mathrm{m}$. The FGMs are usually made of 10-25 layers, allowing for the tailoring of specific thermodynamic paths during experimentation [8].

The pressure profiles in Fig. 2 were obtained from simulations (CALE) carried out at LLNL. Five experiments, A $(1700 \mathrm{~m} / \mathrm{s}), \mathbf{B}(1260 \mathrm{~m} / \mathrm{s}), \mathbf{C}(730 \mathrm{~m} / \mathrm{s}), \mathbf{D}(1760 \mathrm{~m} / \mathrm{s})$ and E $(1260 \mathrm{~m} / \mathrm{s})$, were carried out, with A experiencing the highest pressure of $51.5 \mathrm{GPa}$ and $\mathbf{C}$ experiencing the lowest pressure of $17.7 \mathrm{GPa}$. Table 1 shows the pressures, strains and strain rates achieved in the different experiments. Two distinct pressure profiles were attained, one having a hold-time of approximately $10 \mu$ s ('long pulse') and one having almost no hold 
time (or a "short pulse"), relatively. The long-pulse samples belong to experiments A, B and C, and the short-pulse samples belong to D and E. It should be noted that the "long-pulse" samples also exhibited a spike or shock at the onset of the pulse duration due to the experimental setup, and the likely effect on the microstructural deformation processs is also discussed in the results section. The as-received samples belonging to each batch were in the form of cylindrical specimens having an average diameter and thickness of $6 \mathrm{~mm}$ and $3.6 \mathrm{~mm}$, respectively. Analysis of these samples enabled the comparison of the deformation mechanisms activated at this broad range of pressures. The strain rate versus pressure plot for these ICE experiments is given in Fig. 3. Strain rates achieved were on the order of $10^{4} / \mathrm{sec}$,

$10^{4}$ to $10^{5}$ orders of magnitude lower than shock experiments. A comparison of the current data with shock experiments is provided in Section 4.0.

\subsection{Micro-Hardness Measurements}

Microhardness measurements were performed on all monocrystalline samples. After polishing to eliminate the heat affected zone $(\sim 50 \mu \mathrm{m}$ on each side) and provide a smooth surface, the top surface was indented using a Vickers tip attached to a Leco: M-400-H1 microhardness machine. The load applied was $200 \mathrm{gF}$, with a hold time of $15 \mathrm{sec}$.

\subsection{TEM Sample Preparation}

Cylindrical cuts having a diameter of $3 \mathrm{~mm}$ were made through the center of each specimen by EDM (Electron Discharge Machined). Fig. 4(a) shows a typical as-received sample. TEM specimens were then sliced from each cylinder, as shown in Fig. 4(b). The specimens were further polished down using 1200, 2400, and 4000 grit paper, respectively, to approximately $100 \mu \mathrm{m}$. The foils were electropolished using a solution of $7 \% \mathrm{H}_{2} \mathrm{SO}_{4}$ in methanol for TEM imaging. 


\subsection{RESULTS AND DISCUSSION}

\subsection{Microhardness Results}

An interesting trend in hardness was observed. The value increases with peak pressure until approximately $45 \mathrm{GPa}$, as illustrated in Fig. 5. It then saturates and begins to drop off dramatically. It can be seen that the hardness value at $52 \mathrm{GPa}$ is almost two-thirds that of the intermediate pressure samples. It is hypothesized that the drop in hardness may be due to recovery processes due to melting taking place at the impact surface. This can be caused by the elevated temperature rise occurring at the higher peak-pressure conditions. Figure 5 shows this rise in temperature as the peak pressure increases.

\subsection{TEM Results}

TEM results are presented next beginning with the highest peak pressure experiments. Although other deformation microstructures are emphasized, it should be noted that dislocation substructures such as cells and laths were the most abundant. Diffraction patterns taken from all samples investigated revealed a [001] crystal orientation, as seen in Fig. 6, confirming that sample orientation is not a variable in this study.

\subsubsection{Experiment A: $52 \mathrm{GPa}$}

TEM samples analyzed from A revealed various deformation substructures. Dislocation activity was most abundant. However, other deformation features were found. At approximately $0.1 \mathrm{~mm}$ from the impact surface, the microstructure predominantly consisted of dislocation activity with some limited evidence of twining. Fig. 8 shows very clear twinned regions. The extra spots in the diffraction pattern confirmed the existence of these twins. At a beam direction $\mathrm{B}=[011]$, both small and large twins were observed having $(\overline{1} \overline{1})$ twin habit planes. These micro-twins are embedded within dislocated laths running along the same direction as the twins.

A more close-up view of these micro-twins can be seen in Fig. 8. The smallest twins measured had a length of approximately $80 \mathrm{~nm}$, and the longest twins were on the order of $1.5 \mu \mathrm{m}$. Longer twins 
existed in the TEM images, but they ran across the entire image and their full length was not captured. The micro-twins captured in Fig. 8 clearly have $(\overline{1} 1 \overline{1})$ twin habit planes. Dislocated laths can be seen running along the same direction as the twins. More TEM images at $0.1 \mathrm{~mm}$ from the surface (Fig. 9) taken with $B=[001]$ showed twin features running along the [ $\overline{2} 20]$ and [220]. The two twin variants are present at 90 degrees from one another. In certain remote areas, stacking faults were captured intersecting each other. The bands are thicker than those observed above. Note in Fig. 10 that, just as in the previous case, one variant runs along [220] and the second variant runs perpendicularly to it along [220]. The substructure seems to have relaxed from the microstructure present above it into these thicker features.

Single lath variants were also evident in some regions at this same depth. Dislocation cells were very small and almost indiscernible. Fig. 11 reveals these lath-like features and dislocation activity. The features are in agreement with the "wavy sub-grains" observed after high-pressure shock compression of copper by Murr [9]. This lath structure is also analogous to the one observed by Gray [10] in specimens where the residual strain was high. It is suggested that the substructures are due to thermal recovery of the microstructure. Note that, at a beam direction $\mathrm{B}=[001]$, the laths run along the [220] direction.

At $0.7 \mathrm{~mm}$ from the impact surface, heavily dislocated laths having an average thickness of approximately $0.6 \mu \mathrm{m}$ were observed. Fig. 12(a) shows these laths at a beam direction $\mathrm{B}=[001]$. They run along the [220] direction. At $1.2 \mathrm{~mm}$ from the surface, heavily dislocated laths running across the sample was also evident. The average thickness of the laths at this distance was $0.7 \mu \mathrm{m}$, as seen in Fig. 12(b). The laths extend along the [220] direction.

Additionally, twinning, confirmed by a diffraction pattern with beam direction $B=[011]$, was evident at this depth (shown in Fig. 13). The twins are exhibit a [11 $\overline{1}]$ habit plane. Note the heavy dislocation activity surrounding the twinned regions. At $1.2 \mathrm{~mm}$ into the sample, dislocation cells were distinguishable, and the measurement of their sizes was possible. The average dislocation cell size at this depth was $0.15 \mu \mathrm{m}$, Fig. 14. At $1.8 \mathrm{~mm}$ into the sample, heavy dislocation activity was predominant, with dislocation cells of approximately $0.2 \mu \mathrm{m}$. Twinning was still evident (not shown here) as well. 


\subsubsection{Experiment D: $44 \mathrm{GPa}$}

Dislocation cells were the predominant deformation substructure in the samples belonging to this group. Diffraction patterns with beam direction $B=[001]$ confirmed the [001] crystal orientation of all samples investigated. At $0.15 \mathrm{~mm}$ (the closest distance from the impact surface investigated) within the specimen, dislocation cells with an average cell size of $0.36 \mu \mathrm{m}$, seen in Fig. 14(a), were evident. At approximately $2 \mathrm{~mm}$ (the farthest from the impact surface investigated) within the specimen, dislocation cells with an average cell size of $0.43 \mu \mathrm{m}$, seen in Fig. 14(b) were evident. A summary of dislocation cells sizes at all the pressures investigated is given in Figs. 22 and 24 at the end of this section. Besides dislocation cells, other deformation features such as dislocated laths were present, as seen in Fig. 15. This image was taken at $0.15 \mathrm{~mm}$ from the impact surface with the beam incident in the [001] direction. The laths are elongated in the $[\overline{2} 20]$ direction, consistent with the orientation of bands observed in experiment $\mathbf{A}$ at $52 \mathrm{GPa}$.

At $0.77 \mathrm{~mm}$ from the impact surface, dislocation cells (not shown here) with an average cell size of $0.46 \mu \mathrm{m}$ were predominant. Long laths/bands of dislocation walls were also observed in the sample, as seen in Fig. 16(a). Consistent with previous observations, the bands run along the [220] direction. One interesting observation comprised of two dislocated lath variants intersecting at a point, Fig. 16(b). This is the same exact phenomenon observed at $0.1 \mathrm{~mm}$ (Fig. 10), where dislocated laths running along the [220] and [ $\overline{2} 20]$ directions intersect. At $1.34 \mathrm{~mm}$ and $1.85 \mathrm{~mm}$ further into the impacted sample, additional dislocation cells (not depicted here) having an average cell size of $0.38 \mu \mathrm{m}$ and $0.43 \mu \mathrm{m}$, respectively, were evident.

\subsubsection{Experiment B: $34 \mathrm{GPa}$}

Dislocation cells were predominant at $0.14 \mathrm{~mm}$ from the impact surface of the specimens investigated in this group. The average cell size measured was $0.26 \mu \mathrm{m}$. At a distance of approximately $0.6 \mathrm{~mm}$, dislocation cells (note shown here) with an average cell size of $0.25 \mu \mathrm{m}$ were measured. Dislocation bands were also observed at $0.6 \mu \mathrm{m}$, seen in Fig. 17(a), 
running in the [220] direction. Two lath variants elongated in the [220] and [2र0] were also seen intersecting, Fig. 17 (b). This is consistent with previous observations in A and D.

At a depth of $0.7 \mathrm{~mm}$, dislocation cells with an average dislocation cell size of approximately $0.3 \mu \mathrm{m}$ were the major deformation microstructure. However, heavily dislocated lath-like features were still evident as well. At approximately $1 \mathrm{~mm}$ from the surface, dislocation cells with sizes equivalent to that at $0.7 \mathrm{~mm}$ were predominant. An area within this depth revealed intersecting laths surrounded by dislocation activity, as seen in Fig. 18. The laths seem to act as either barriers to dislocation motion, thus, locking them in or as nucleation sites for dislocation activity. At $1.5 \mathrm{~mm}$, dislocation cells (not shown here) with an average cell size of approximately $0.3 \mu \mathrm{m}$ were evident. Long laths/needle-like features with trapped in dislocations, identical to Fig. 17(a), were also observed in a small region. They were also stretched along the [220] direction.

\subsubsection{Experiment E: 26 GPa}

Dislocation cells were the most abundant deformation features unveiled in this pressure condition. The average dislocation cell size increased from $0.4 \mu \mathrm{m}$ at $0.25 \mathrm{~mm}$ within the sample to $0.5 \mu \mathrm{m}$ at $2.7 \mathrm{~mm}$. The other features such as stacking faults, dislocated laths and elongated cells were revealed in a few of the specimens explored, but they were not as abundant and occupied a much smaller area than the cells. At $0.9 \mathrm{~mm}$ from the surface, stacking faults were evident in a few isolated regions. Fig. 19(a) shows an example of such a region. The spacing between the stacking fault bands is approximately $0.1 \mu \mathrm{m}$. One stacking fault variant stretches along the $[\overline{2} 20]$ direction. Further evidence of the same stacking fault variant was seen at $1.3 \mathrm{~mm}$ from the impact surface, Fig. 19(b). The thickness of the features was larger, however, since the microstructure did not experience as high of a pressure as the sample above it due to the pressure decay with distance.

At the same depth, narrow and heavily dislocated laths or possibly stacking faults were observed, as seen in Fig. 20(a). The two variants perpendicular to each other (running in the [220] and [ $\overline{2} 20])$ intersect each other. The orientation of these two intersecting lath variants is consistent with previous observations. An interesting area (not shown here) within the 
sample at roughly $1.8 \mathrm{~mm}$ consisted of small twin-like features surrounded by a sea of dislocation cells, similar to that in Fig. 16(a). At $2.3 \mathrm{~mm}$ from the impact surface, dislocated laths and elongated dislocation cells, as seen in Fig. 20(b), were revealed. The elongated cells are stretched along the same [220] orientation as the laths. This detail leads to the hypothesis that the laths at higher pressures closer to the impact surface relax into these elongated cells (and successively into regular dislocation cells) at lower pressures further away from the impact surface.

\subsubsection{Experiment C: $18 \mathrm{GPa}$}

Relatively large dislocation cells were the most abundant deformation feature for this lowest pressure condition. The average dislocation cell size varied from approximately 0.5 $\mu \mathrm{m}$ at $0.13 \mathrm{~mm}$ within the specimen to $0.6 \mu \mathrm{m}$ at $2 \mathrm{~mm}$. Elongated cells and some lath-like activity were noticed in some regions, in particular closest to the impact surface at approximately $0.1 \mathrm{~mm}$ within the sample. Fig. 21 perfectly chronicles the findings in this pressure group. Both cells and dislocated lath-like features relaxing into elongated cells can be seen. The orientation of the laths/elongated cells is along the [220] direction. This observation is in compliance with the orientation of the laths revealed in the earlier experiments.

The plot shown in Fig. 22, summarizes the change in cell size with distance into the sample for the various pressure conditions considered. It can be seen that the cell size gradually increases with distance away from the impact surface for each pressure condition. This is consistent with previous investigations by $[2,9,10]$. In comparing the relative cell sizes of all the pressure conditions, two specifics that interfere with ideal experimental conditions need to be noted. First, experiments A, B and $\mathbf{C}$ were subjected to a much longer pulse duration than that of $\mathbf{D}$ and $\mathbf{E}$. The pulse duration was approximately $10 \mu$ s for $\mathbf{A}, \mathbf{B}$ and $\mathbf{C}$ as compared to almost $1 \mu$ s for $\mathbf{D}$ and $\mathbf{E}$. Second, the CALE simulations reveal that $\mathbf{A}, \mathbf{B}$ and $\mathbf{C}$ exhibit an unfavorable phenomenon; a slight shock at the onset of the pulse duration (due to the experimental setup). Experiments $\mathbf{D}$ and $\mathbf{E}$ are, therefore, "purely" quasi isentropic experiments as compared to the rest. 
The cell sizes measured for $\mathbf{D}$ are not in agreement with the measurements from the other experiments. Note that although D experiences a higher peak pressure (44 GPa) than B (34 GPa), it has larger cells. The cells in $\mathbf{D}$ are also very close in size to those of $\mathbf{E}$, the other "short-pulse" experiment. This inconsistency may be attributed to the fact that $\mathbf{D}$ and $\mathbf{E}$ did not experience a slight shock, and as a result, less strain in the form of dislocation cells was accumulated in the samples. Fig 22(b) shows the change in cell size as a function of strain. The cell-sizes clearly decrease with increasing strain as is expected (with the exception of $\mathbf{D}$ ). Bassim and coworkers [12-15] have performed studies on the decrease in dislocation cell size with strain on copper and steel and their work is consistent with our observations.

The "long-pulse" experiments, A, B and C, show a clear decrease in the average dislocation cell size with increasing peak pressure, consistent with prior work on high strain rate deformation of metals $[2,9,10]$. In their work, Meyers and Murr [9, 11] note that dislocation cell structures are mostly dependent upon peak pressure and the time available to move these dislocations into arrays characterized by cell dimensions and wall size and structure. The dislocation cell size is determined by the peak pressure whereas the wall structure and recognition of the cell structure are determined to a degree by the pulse duration. There is no controversy as to the effect of peak pressure on dislocation cell-size. The disagreement lies in the effect of pulse duration on dislocation structures. It is understood that dislocation cell walls become better defined as pulse duration increases, because of the available time for dislocations to reorganize into more stable energy configurations. Some experimental studies and simulations, however, have shown that dislocation density is proportional to pulse duration [16, 17]. This observation is plausible in our case as it may explain the reason as to why the dislocation cell-size is smaller in $\mathbf{B}$ than in $\mathbf{D}$.

\subsection{COMPARISON: ICE VS. SHOCK}

A comparison of the recovered microstructure revealed in the quasi-isentropic compression experiments is made with that of shock compressed copper. Shock compression can be achieved by various methods. In this case, shock attained by both explosively driven flyer plates and direct laser drives is considered. The work of B. Cao et al [1] on flyer-plate 
shock and Schneider et al [2] on laser-shock of [001] copper is drawn upon. The peak pressures investigated in both cases are within the range of that studied in the ICE experiments (approximately $20 \mathrm{GPa}$ to $60 \mathrm{GPa}$ ), ideal for comparison purposes. In the case of flyer plate impact, an explosion drives a plate that impacts a target at a known velocity. The strain rates typically achieved and reported in literature are on the order of $10^{6} 1 / \mathrm{s}$, and pulse durations are on the order of 0.1 to $0.2 \mu \mathrm{s}$. This long pulse duration (also experienced in experiments $\mathbf{A}, \mathbf{B}$ and $\mathbf{C}$ of the ICE experiments) allows shock generated defects to reorganize into lower energy configurations and allows more time for annealing and recrystallization to take place. Laser shock, on the other hand, is achieved by the rapid heating created by laser pulses illuminated on the material's surface. Strain rates reported in these experiments are on the order of $10^{9} 1 / \mathrm{s}$, and the pulse durations are on the order of $5 \mathrm{~ns}$. Due to the very short pulse duration, the pressure decay in the sample is very rapid and postshock heating is minimized.

Shock experiments are dictated by the following Swegle-Grady expression:

$$
\dot{\varepsilon}=7.84 \times 10^{-33} \times P^{4}
$$

Where as the isentropic experiments have the following relationship:

$$
\dot{\varepsilon}=1.17 \times 10^{-7} \times P^{1.1}
$$

The Fig. 23(a) compares the different strain rate regimes attained in shock and ICE. It is clear thart strain rates achieved in shock are on the order of $10^{9} / \mathrm{sec}, 10^{4}$ to $10^{5}$ orders of magnitude higher than ICE experiments. Fig. 23(b) shows the temperature rise in both cases. Clearly, the temperature rise is more severe in shock at higher peak pressures as compared to ICE. The temperature rise date for the ICE experiments was obtained from CALE simulation data, and the data for shock was from thermodynamically calculated data for copper.

\subsection{Comparison of Deformation Substructures: 18-30 GPa}

As discussed previously, dislocation activity was the main deformation behavior in the quasi-ICE experiments at $18 \mathrm{GPa}$. At $20 \mathrm{GPa}$, laser shock experiments exclusively contain well-defined cellular dislocations (not shown here) with an average cell size diameter between 0.2 and $0.3 \mu \mathrm{m}$ [2]. This result is in accordance with previous investigations on 
laser-shock by Murr [9]. The pulse duration was, however, 10 to 100 times higher in Murr's work. The plot in Fig. 24 shows that the dislocation cell-size in laser shock is significantly lower than in quasi-isentropic compression $(0.25 \mu \mathrm{m}$ versus $0.5 \mu \mathrm{m})$. This is attributed to the much higher strain-rates achieved during laser-shock. The pulse duration is much higher in the ICE experiments, allowing for the defect substructures to relax and form a more stable energy configuration, and hence, larger dislocation cells. Some evidence of staking faults (Fig. 19), as previously reported, was observed at $26 \mathrm{GPa}$ in the ICE experiments. Stacking faults were seen at the higher pressure regimes in both flyer plate and laser shock (discussed next), but not between 18 and 30GPa. In their work, B. Cao et al. [1] carry out experiments at $30 \mathrm{GPa}$ and above. A comparison of the defect substructure for this pressure group with flyer-plate experiments is not made because of the lack of published data.

\subsection{Comparison of Deformation Substructures: 30-40 GPa}

Some similarity between all three cases was found in this range. In laser shock, this pressure regime produced dense dislocation tangles, stacking faults, and micro twins. Fig. 25(a) shows staking faults and dislocation tangles marked as DT and SF. There are no readily discernable dislocation cells, a clear indication of the pressure dependence of the deformation mechanisms. All four stacking fault variants viz the partial dislocations (11i) 1/6[112],

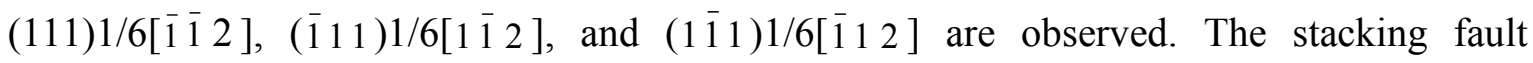
variants are along the same orientation in all three cases. Given the incident energy input as parallel to [001], it is not surprising that all four stacking fault variants are activated in laser shock since they have the same critical resolved shear stress. The density of occurrence of the stacking faults along the $[\overline{2} 20]$ is, however, greater than along [220] in laser shock. . In ICE, the stacking faults and laths that are most abundant run along the [220] and $[\overline{2} 20]$ (Fig. 16(b), 19, 18, 20(a)). However, their occurrence is less frequent and not as abundant as in laser shock and flyer plate experiments. This is attributed to the difference in the strain rate regime in ICE (less by a factor of 10 to 100 ).

For the flyer plate experiments, staking fault patterns similar to shock are observed at 30 GPa. Fig. 25 shows the two sets of stacking faults along $[\overline{2} 20]$ and $[220]$ in the (001) plane, 
where the TEM electron beam direction is [001]. These orientations are consistent with ICE experiments, since the same partial dislocations are active in both cases. The average spacing between the stacking faults is between 230 and $450 \mathrm{~nm}$ for laser shock and between 180 and $220 \mathrm{~nm}$ for flyer-plate impact. The spacing in the ice experiments ranges between 100 and $500 \mathrm{~nm}$.

\subsection{Comparison of Deformation Substructures: 40-60GPa}

In laser shock, the deformation microstructure at $55 \mathrm{GPa}$ consists of a high density of micro-twins (Fig. 26(a)) and laths (Fig. 26(b)). Two sets of micro-twins are observed when imaged at $\mathrm{B}=\left[\begin{array}{lll}0 & 0 & 1\end{array}\right]$. They appear at exactly 90 degrees from one another aligned along [ $\left.\begin{array}{lll}2 & 2 & 0\end{array}\right]$ (set A) and [ $\left.\begin{array}{lll}\overline{2} & 2 & 0\end{array}\right]$ (set B) directions, respectively, and they are present roughly in same proportion (not shown here). When imaged in the edge orientation at B close to [ $\left.\begin{array}{lll}1 & 0 & 1\end{array}\right]$, Figure 26(a), the micro-twins from set A have the (111) habit plane and are elongated along [1 $\overline{2} 1]$. This set of micro-twins exhibits a wide range of lengths, from as small as $70 \mathrm{~nm}$ to as large as $1 \mu \mathrm{m}$; In contrast, the set B micro-twins have a near uniform length of $70 \mathrm{~nm}$. Correspondingly, these two same twin variants running along [220] $\overline{2} 20]$ were also captured in the ICE experiments at 52GPa (Fig. 7 and 9).

Unlike the micro-twins, the laths in laser-shock are elongated close to $<220>$. In some

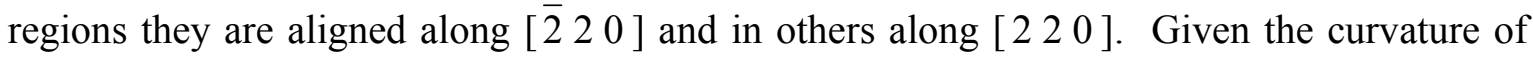
the laths it is unlikely that they conform to any single habit plane. The lath interface plane is parallel to [001] and therefore uniquely different from micro-twins. This microstructure represents the recovered state of a heavily twinned and dislocated structure. These laths are very identical to those observed in the ICE experiments at $52 \mathrm{GPa}, 0.7 \mathrm{~mm}$ and $1.2 \mathrm{~mm}$ from the impact surface. A striking similarity can be seen between the laths depicted in Fig. 26(b) and those in Fig. 12. The laths in ICE are not oriented along the [220] direction, as reported in laser-shock.

The flyer-plate samples shocked at $57 \mathrm{GPa}$ revealed deformation bands, slip bands, recrystallized regions, dislocation tangles and some micro-twins. Only one set of micro-twins 
was observed having a ( $\overline{1} \overline{1}$ 1) habit plane, as seen in Fig. 27(a). The sizes of the micro-twins vary from $80 \mathrm{~nm}$ to $180 \mathrm{~nm}$. Interestingly, the same micro-twin variant was observed in the ICE experiment at $52 \mathrm{GPa}$, Fig. 8, elongated along the $\overline{2} 20]$ direction. In one of the flyerplate samples, a deformation band having a width of $1.8 \mu \mathrm{m}$ is seen running diagonally along the sample, Fig. 27(b), intersecting smaller neighboring slip/stacking faults. Selected area diffraction identifies the vertical slip as $(1 \overline{1} 1)$.

The average width of the stacking faults observed was approximately 500nm. Further into the sample, regular dislocation cell arrays running across the sample were observed (not shown here). Dislocation tangles between these arrays were also evident. The distance between the dislocation arrays were approximately 500nm as well leading to the hypothesis that the arrays are due to the recovery or relaxation of the stacking-fault arrays. Similar to all three experiments, a decrease in dislocation density with depth into the sample is evident. Unlike the features seen in laser shock and ICE, fully recrystallized regions were seen in the flyer-plate experiments.

\subsection{CONSITUITIVE MODELING}

Two separate models to predict the twinning threshold using the Preston-Tonks-Wallace and Zerilli-Armstrong constitutive equations are presented, respectively. These models determine the critical pressure for twinning in both shock and ICE regimes. It is well-known that different metals have different threshold twinning pressures. In the case of FCC metals, this pressure is a function of stacking-fault energy [18]. Slip and twinning twinning are visualized as competing mechanisms, where slip is a temperature and strain-rate dependent phenomenon and twinning is much less sensitive to these variables.

\subsection{PTW MODEL}

Using the general approach of Murr et. al. [19] and Meyers et. al. [20], we estimate the twinning threshold pressure for quasi-isentropic and shocked regions by considering the constitutive response of copper for the two regimes, shockless and shocked. The twinning threshold is taken to be the point at which the tensile flow stress (e.g., $2 \tau)$ is equal to the 
tensile twinning stress, taken to be $490 \mathrm{MPa}$ [20] in this work, and is assumed to be temperature and strain rate independent.

A number of models have been developed to estimate the flow stress as a function of strain rate and temperature $[17,18]$ and additionally pressure [23, 24-25]. With the exception of the Preston-Tonks-Wallace (PTW) constitutive description [23], none that allow for a pressure dependence are applicable over the range including both the thermal activation regime and the dislocation drag regime. Thus, in estimating the flow stress we will employ the model developed by PTW [23] as it is well suited for the very high strain rates in the experiments considered. If we restrict our analysis to constant strain rate paths, the instantaneous flow stress can be calculated from:

$$
\tau=\hat{\tau}_{s}+\frac{1}{p}\left(s_{0}-\hat{\tau}_{y}\right) \ln \left\{1-\left[1-\exp \left(-p \frac{\hat{\tau}_{s}-\hat{\tau}_{y}}{s_{0}-\hat{\tau}_{y}}\right)\right] \exp \left[\frac{-p \theta \psi}{\left(s_{0}-\hat{\tau}_{y}\right)\left[\exp \left(p \frac{\hat{\tau}_{s}-\hat{\tau}_{y}}{s_{0}-\hat{\tau}_{y}}\right)-1\right]}\right]\right\}
$$

where we have preserved the notation used in [23] for simplicity. The work hardening saturation stress and yield stress in the thermal activation regime are given by:

$$
\begin{aligned}
& \hat{\tau}_{s}=s_{0}-\left(s_{0}-s_{\infty}\right) \operatorname{erf}[\kappa \hat{T} \ln (\gamma \dot{\varepsilon} / \dot{\psi})\rfloor \\
& \hat{\tau}_{y}=y_{0}-\left(y_{0}-y_{\infty}\right) \operatorname{erf}[\kappa \hat{T} \ln (\gamma \dot{\varepsilon} / \dot{\psi})\rfloor
\end{aligned}
$$

where $s_{0}, s_{\infty}, y_{0}$, and $y_{\infty}$, are the values $\hat{\tau}_{s}$ and $\hat{\tau}_{y}$ take at zero and very high temperature respectively, $\dot{\psi}$ is the plastic strain rate, $\hat{T}$ is the homologous temperature and erf is the error function. The flow stress is normalized to the shear modulus, G. e.g., $\hat{\tau}_{y}=\tau_{y} / G$. The parameters $\kappa, \gamma$ are dimensionless material constants and $d$ is given by:

$$
\dot{\varepsilon}=\frac{1}{2}\left(\frac{4 \pi \rho}{3 M}\right)^{1 / 3} \sqrt{G / \rho}
$$

where $M$ is the atomic mass and $\rho$ is the density. Where appropriate the temperature dependence of the shear modulus was approximated as $G(\rho, T)=G_{0}(\rho)(1-\alpha \hat{T})$, 
where $G_{0}(\rho)$ is the zero temperature modulus as a function of density and $\alpha$ is a material constant. The pressure dependence of the model is due to the pressure dependence of the shear modulus.

In the strong shock regime the behavior is given by:

$$
\begin{aligned}
& \hat{\tau}_{s}=s_{0}(\dot{\psi} / \gamma \dot{\varepsilon})^{\beta} \\
& \hat{\tau}_{y}=s_{0}(\dot{\psi} / \gamma \dot{\varepsilon})^{\beta}
\end{aligned}
$$

where $\beta$ is a material constant and $s_{0}$ and $\gamma$ are employed for continuity. In order to accommodate the observed increase in strain rate sensitivity at moderate strain rates an additional dependency is included as:

$$
\hat{\tau}_{y}=y_{1}(\dot{\psi} / \gamma \dot{\varepsilon})^{y_{2}}
$$

where $y_{1}$ and $y_{2}$ are material constants.

The complete model is:

$$
\begin{gathered}
\hat{\tau}_{s}=\max \left\{s_{0}-\left(s_{0}-s_{\infty}\right) \operatorname{erf}[\kappa \hat{T} \ln (\gamma \dot{\varepsilon} / \dot{\psi})], s_{0}(\dot{\psi} / \gamma \dot{\varepsilon})^{\beta}\right\} \\
\hat{\tau}_{y}=\max \left\{y_{0}-\left(y_{0}-y_{\infty}\right) \operatorname{erf}[\kappa \hat{T} \ln (\gamma \dot{\varepsilon} / \dot{\psi})] \min \left[y_{1}(\dot{\psi} / \gamma \dot{\varepsilon})^{y_{2}}, s_{0}(\dot{\psi} / \gamma \dot{\varepsilon})^{\beta}\right]\right\}
\end{gathered}
$$

The model provides a smooth transition between the thermal activation regime and the strong shock regime.

In using the model to describe the $<100>$ single crystal used in this investigation the model parameters were slightly modified to match the low strain rate work hardening behavior for $<100>$ copper displayed in [18]. In particular the work hardening rate, $\theta$, was adjusted to a value of 0.01 and saturation stress, $s_{0}$, to a value of 0.0045 . All other parameters are as given in [23]. Although the flow behavior is a function of strain, strain rate, and temperature, at very high strain rates the flow stress is essentially at the saturation value for all values of strain. In the shockless region, the temperature, strain, and strain rate from the hydrodynamic solution previously presented were used. In the shocked region, the temperature and strain were taken from the simulations while the strain rates were 
determined as outlined above (Eqn. 1). It has also been assumed that the flow stress and twinning stress, being dependent on the atomic energy barrier, scale with the shear modulus, as is typical in high pressure constitutive models.

Results of these calculations are presented in Fig. 28 where the flow stress, as a function of peak drive pressure, for the shockless and shocked region are plotted. The twinning threshold was assumed to vary with pressure (or equivalently density) through the density dependence of $G$ :

$$
\sigma_{T}(P)=\sigma_{T}^{0} \frac{G(T, P)}{G_{0}}
$$

where $\sigma_{T}^{0}$ and $G_{0}$ are the twinning threshold stress and shear modulus at ambient pressure respectively. It can be seen from the figure that the slip-twinning transition in shock loading is approximately $18 \mathrm{GPa}$, in agreement with literature [2]. The steep shock loading curve arises due to the high strain-rate dependence on both the shock pressure and flow stress [6]. On the other hand, the isentropic gas-gun condition does not transition into the twinning regime and a critical twinning stress is, therefore, not reached. This is inconsistent with experimental observations, since twinning was observed at $\sim 52 \mathrm{GPa}$. The presence of the shock at the start of the shock pulse (Fig. 2) for this pressure condition creates a deviation from quasi-isentropic conditions and may be accountable for the presence of the twins observed.

\subsection{ZERILLI-ARMSTRONG MODEL}

In this model, $300 \mathrm{MPa}$ is the value adopted as the twinning threshold in monocrystalline copper [26], and for simplicity, it is assumed that this value is constant at all imposed pressures (i.e. independent of temperature and strain-rate effects). The dependence of strainrate on pressure in both shock and ice is given by equations (1) and (2), respectively, and the strain $(\varepsilon)$ can be calculated from the following momentum balance equation [18]:

$$
P=\frac{C_{0}^{2}\left(1-e^{3}\right)}{V_{o}\left[1-S\left(1-e^{\varepsilon}\right)\right]^{2}}
$$


A work-hardening function $f(\varepsilon)$, however, is incorporated that represents the behavior of the stress-strain curve for monocrystalline copper with the closest orientation to [001]. This polynomial, equation (14), is taken from Diehl [27].

$\sigma_{o} f(\varepsilon)=45510 \varepsilon^{6}-86899 \varepsilon^{5}+63406 \varepsilon^{4}-21834 \varepsilon^{3}+2901.8 \varepsilon^{2}+464.8 \varepsilon-1.92 \mathrm{MPa}$

The temperature rise associated with shock compression and ICE conditions are established by the following two equations (plots in Fig. 22(b)):

$$
\begin{gathered}
T_{\text {shock }}=10^{-19} P^{2}+2 \times 10^{-9} P+295.55 \\
T_{I C E}=318.03+2.75 \times 10^{-9} \times P
\end{gathered}
$$

The constitutive response of copper is given by the Z-A expression below. The values of $\sigma_{G}, C_{3}$, and $C_{4}$ are adopted from [21], and a slight modification to incorporate the strain function, $f(\varepsilon)$, is made.

$$
\sigma=\sigma_{G}+\sigma_{o} f(\varepsilon) \exp \left(-C_{3} T+C_{4} T \ln \dot{\varepsilon}\right)
$$

The results of this model are given in Fig. 29. The Z-A model predicts, just as in the PTW model, that twinning will not occur in the quasi-isentropic experiments, given the range of pressures considered in the experiments. The slip stress never exceeds $300 \mathrm{MPa}$ but is closest at a pressure of $60 \mathrm{GPa}(\sim 250 \mathrm{MPa})$. The evidence of twinning at $52 \mathrm{GPa}$ in the ICE experiments can therefore be attributed to the presence of the initial shock at the onset of the pulse duration. In the case of shock, the twinning threshold is approximately at $30 \mathrm{GPa}$. This result is in agreement with experimental results obtained by Schneider et al. [2]. 


\subsection{CONCLUSIONS}

The deformation substructure of the quasi-isentropic experiments is consistent with what is expected of impact treatment of monocrystalline copper. In the case of the highest pressures of $52 \mathrm{GPa}$, twinning in the monocrystalline sample was evident closest to the impact surface. Dislocated laths, stacking faults and dislocation cells were revealed in the intermediate pressure regimes (30-40 GPa), and dislocation cells were mostly abundant at the lowest pressures $(\sim 20 \mathrm{GPa})$. Dislocation activity decreased with increasing distance from the impact surface for all experiments. This is consistent with work carried out by Schneider et al. [2] on laser shock of copper. The deformation substructure of copper in ICE was similar to that of shock compressed copper. Microstructural observations from Cao et al. [1] and Schneider et al. [2] on flyer-plate and laser shock of [001] copper was similar to our findings.

Modeling of the quasi-isentropic compression condition, using both the Preston-TonksWallace and Zerilli-Armstrong constitutive equations, revealed that twinning should not occur under the pressure regime investigated in these experiments. The presence of twinning in experiments is attributed to the occurrence of an undesirable shock at the onset of the pulse duration due to the experimental set-up. This shock imparts larger strains and strain rates, hence causing twinning.

\section{ACKNOWLEDGEMENTS}

This work was performed under the auspices of the U.S. Department of Energy by University of California, Lawrence Livermore National Laboratory under Contract W-7405-Eng-48. 


\section{REFERENCES}

1. Cao, B. Y., Lassila, D. H., Schneider, M. S., Kad, B. K., Huang, C. X., Xu, Y. B., Kalantar, D. H., Remington, B. A., Meyers, M. A., "Effect of Shock Compression Method on the Defect Substructure in Monocrystalline Copper." In Press: Materials Science and Engineering A.

2. Schneider M.S., Kad, B. K., Kalantar, D. H., Remington, B. A., Meyers, M. A., "LaserInduced Shock Compression of Copper: Orientation and Pressure Decay Effects." Met Trans A, 35 A, 263 (2004).

3. Holmes, N., “ "Shocking” Gas-Gun Experiments, Science and Technology Review, September 2000.

4. Lyzenga, G. A., and Ahrens, T. J., "One-Dimensional Isentropic Compression," in Shock Waves in Condensed Matter, 1981, W. J. Nellis, L. Seaman, and R. A. Graham, Eds., American Institute of Physics Conf. Proceedings No. 78 (1982) 231-235.

5. Barker, L. M., "High Pressure Quasi-Isentropic Impact Experiments", Shock Waves in Condensed Matter, 1984, J.R. Asay, R. A. Graham, and G. K. Straub, Eds., (Elsevier Sci. Pub., Amsterdam).

6. McNaney, J. M., Edwards, M. J., Becker R., Lorenz K. T., Remington B. A., "High Pressure, Laser Driven Deformation of an Aluminum Alloy," Met. Trans A, 35A, pp 265 (2004).

7. Hall, C. A., Asay, J. R., Knudson, M. D., Stygar, W. A., Spielman, R. B., and Pointon, T. D., "Experimental Configuration for Isentropic Compression of Solids using Pulsed Magnetic Loading", Review of Scientific Instruments, 72, 3587 (2001).

8. Nguyen. J. H., Orlikowski, D., Streitz, F. H., Holmes, N. C., and Moriarty, J. A., "Specifically Prescribed Dynamic Thermodynamic Paths and Resolidification Experiments, Shock Compression of Condensed Matter, M. D. Furnish, L.C. Chhabildas, and R. S. Hixson, Eds., AIP Conf. Proc., Melville, New York (2004).

9. Murr, L.E. In: Meyers MA, Murr LE, editors. Shock Waves and High-Strain Rate Phenomena in Metals. NY: Plenum; 1981. p. 607-73.

10. Gray III, G. T. In: Meyers MA, Murr LE, Staudhammer KP, editors. Shock Wave and High Strain Rate Phenomena in Materials. NY: M. Dekker; 1992. p. 899-911.

11. Meyers, M. A. and Murr, L. E. In: Meyers MA, Murr LE, editors. Shock Waves and High-Strain Rate Phenomena in Metals. NY: Plenum; 1981. p. 487-530. 
12. Bassim, M. N. and Klassen, R. J., "Variation in Dislocation Cell Size with Local Strain in a Low Alloy Steel”, Mater. Sci. Eng., 81 (1986) 163.

13. Bassim, M. N. and Bayoumi, M. R., "On Observation of Dislocation Networks During Fracture of Prestrained 4340 Steel", Proceedings of the International Conference on LowEnergy Dislocation Structures", University of Virginia, August 10-13, pp. 317-324, (1986).

14. Bassim, M. N. and Huang, L. B., " Investigation of Dislocation Structuresin Predeformed AISI 4340 Steel”, Mater. Sci. Eng., 96 (1988) 159.

15. Bassim, M. N. and Klassesn, R. J., "A note on the variation of dislocation cell size with strain in HSLA steels", Scr. Metall., 21 (1987) 625.

16. Marsh, E. T. Mikkola, D. E., Scripta Met., 10, 851 (1976).

17. Shehadeh. M. A., Zbib, H. M. and Diaz, R. T. "Multi-Scale Dislocation Dynamics Simulations of Shock Compression in Copper Single Crystal.", International Journal of Plascitcity 21 (2005), 2369-2390.

18. Meyers, M. A., Gregori, F., Kad, B. K., Schneider, M. S., Kalantar, D. H., Remington, B. A., Ravichandran, G., Boehly, T., Wark, J. S., Acta Mat., 51, 12122 (2003),

19. Murr, L. E., Meyers, M. A. , Niou, C-S, Chen, Y-J, Pappu, S. and Kennedy C., Acta Mat., 45, 157 (1997).

20. Meyers, M. A., Voehringer, O. and Lubarda, V. A., "The Onset of Twinning in Metals: A Constitutive Description”, Acta Mat., 49, 4025 (2001).

21. Zerilli, F.J. and Armstrong, R. W., "Dislocation-Mechanics-Based Constitutive Relations for Materials Dynamics Calculations", J. Applied Physics, 61, 1816 (1987).

22. Follansbee, P. S. and Kocks, U. F., "A constitutive description of the deformation of copper based on the use of the mechanical threshold stress as an internal state variable", Acta Met., 36, 81 (1988).

23. Preston, D. L., Tonks, D. L., and Wallace, D. C., "Model for Plastic Deformation for Extreme Loading Conditions", J. Applied Physics, 93, 211 (2003).

24. Steinberg, D. J., Cochran, S. G., and Guinan, M. W., "A Constitutive Model for Metals Applicable at High-Strain Rate”, J. Appl. Phys., 51, 1496 (1980).

25. Steinberg, D. J. and Lund, C. M., "A Constitutive Model for Strain Rates from $10^{-4}$ to $10^{6}$ /s", J. Applied Physics, 65, 1528 (1989). 
26. Thornton, W. G. and Mitchell, T. E., Phil Mag. 7 (1962) 361.

27. Diehl, J., “Zugverformung von Kupfer-Einkristallen”, Z. Metallk. 47 (1956) 33. 
TABLES

Table 1: Pressure Profile data: strain, strain-rate, peak pressure.

\begin{tabular}{|c|c|c|c|c|}
\hline Set No. & Velocity $(\mathbf{K m} / \mathbf{S e c})$ & Strain $(\boldsymbol{\varepsilon})$ & Strain Rate $(\dot{\varepsilon}, \mathbf{1} / \mathbf{s e c})$ & Peak Pressure (GPa) \\
\hline 1354 & 1.7 & -0.3 & $6.49 \times 10^{4}$ & 52 \\
\hline 1352 & 1.76 & -0.23 & $5.67 \times 10^{4}$ & 44 \\
\hline 1353 & 1.26 & -0.21 & $3.69 \times 10^{4}$ & 34 \\
\hline 1351 & 1.26 & -0.15 & $4.44 \times 10^{4}$ & 26 \\
\hline 1355 & 0.73 & -0.11 & $1.80 \times 10^{4}$ & 18 \\
\hline
\end{tabular}




\section{FIGURES}
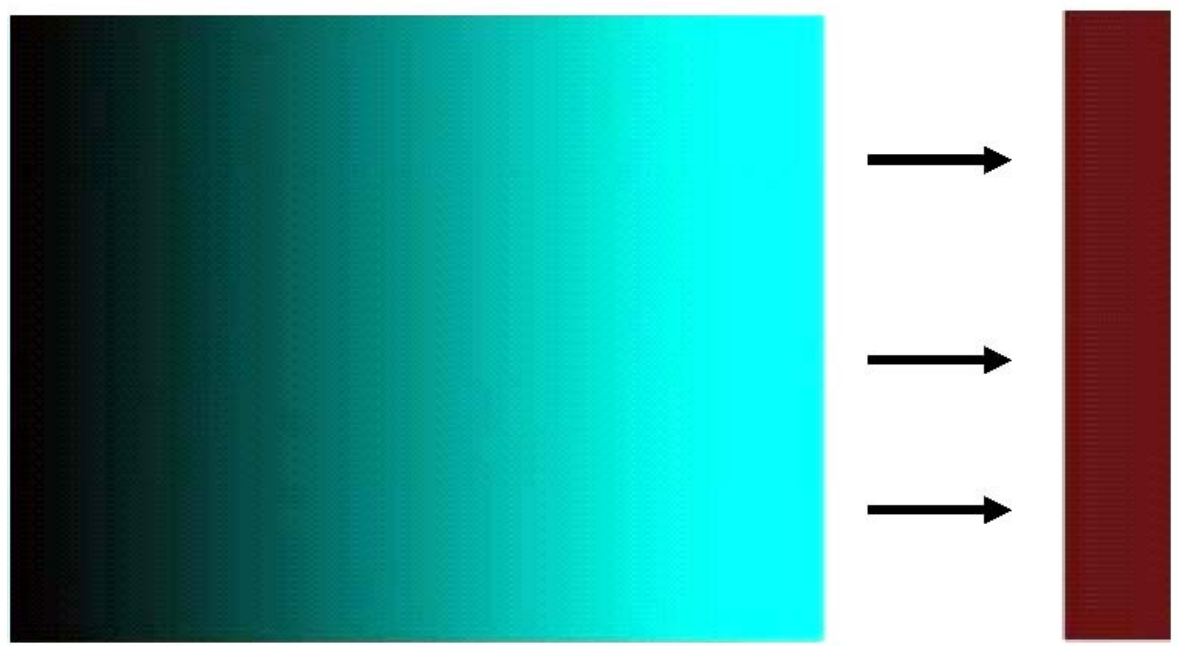

Functionally Graded Target Material (FGM) Impactor

Figure 1: Illustration of FGM impactor hitting a target (darkness proportional to density). 


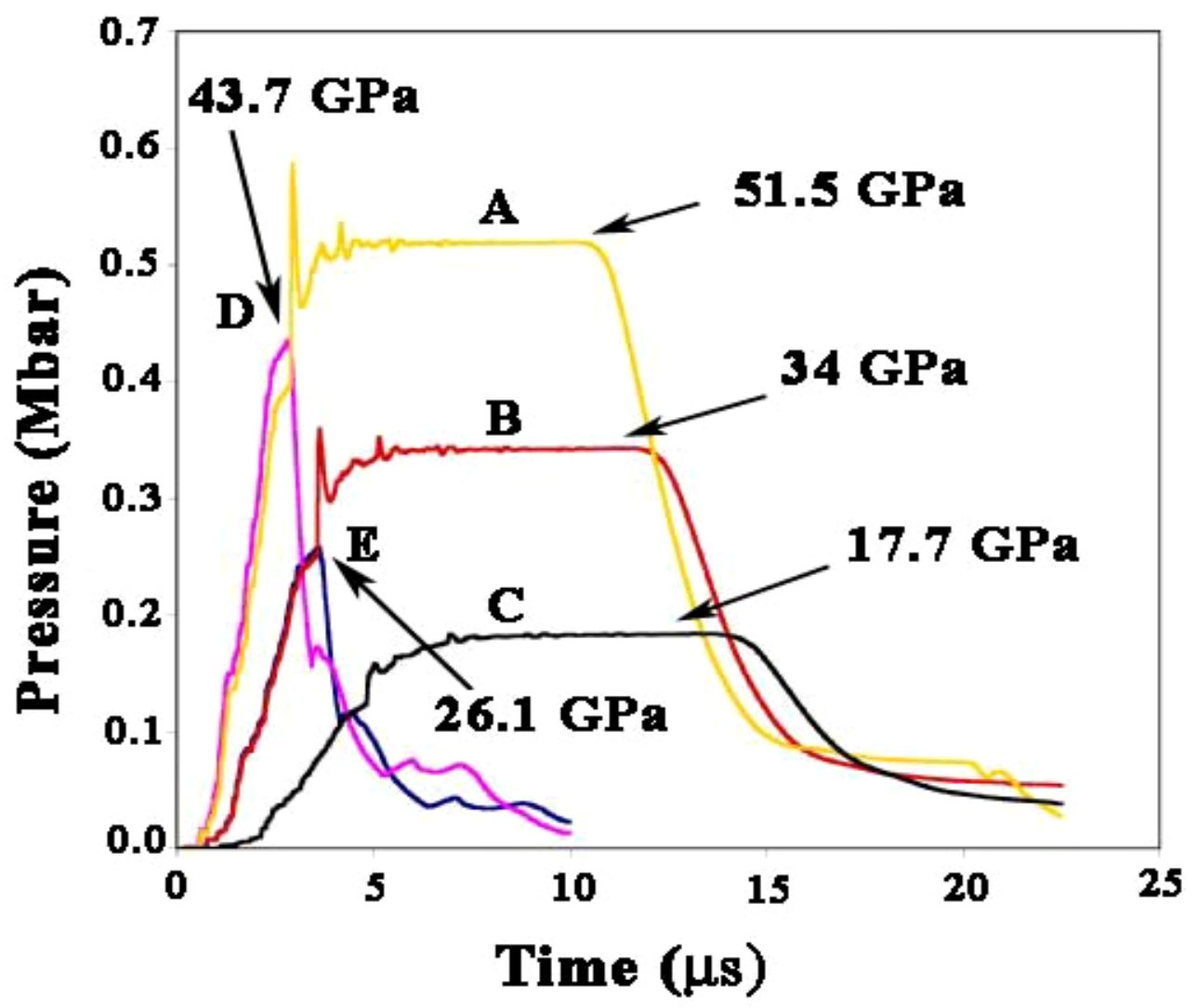

Figure 2: Pressure profiles of ICE experiments. 


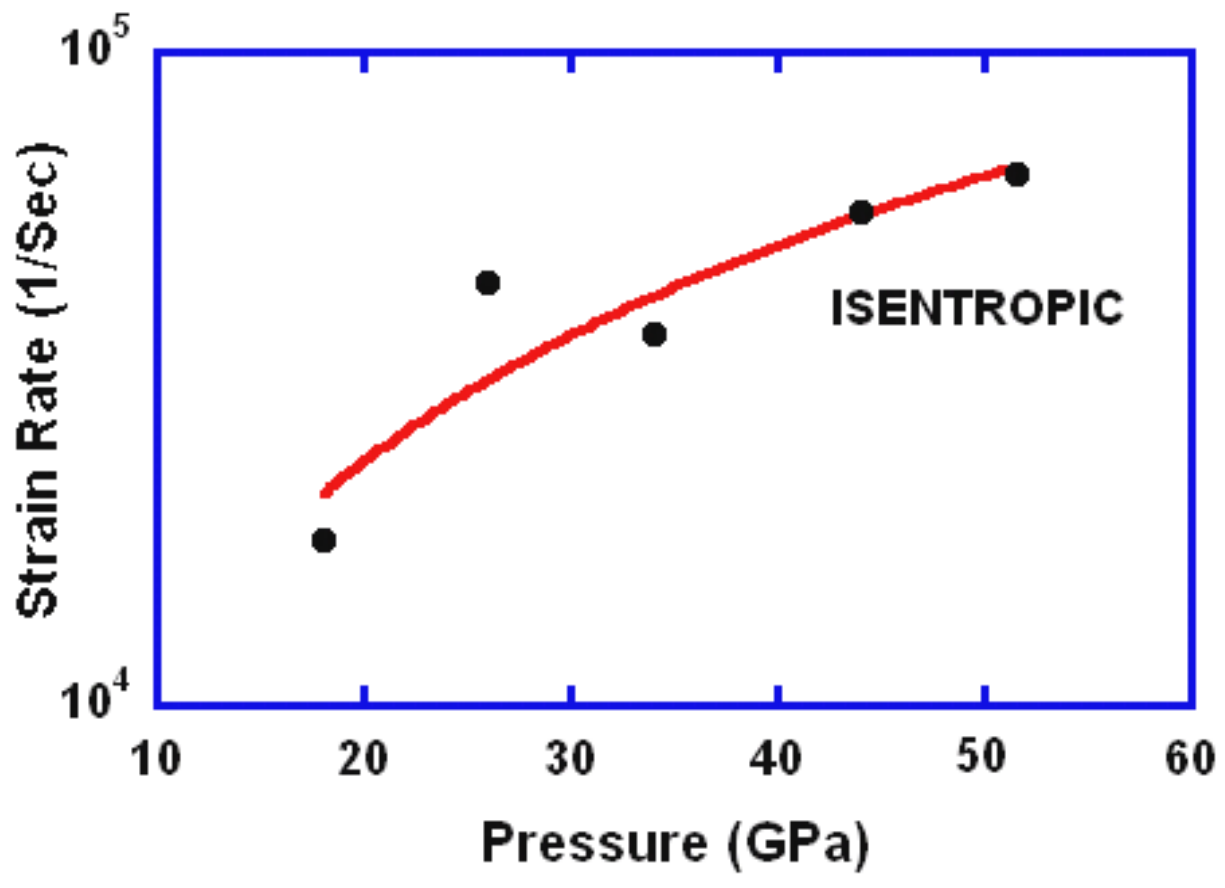

Figure 3: Strain Rate Vs. Pressure for ICE. 


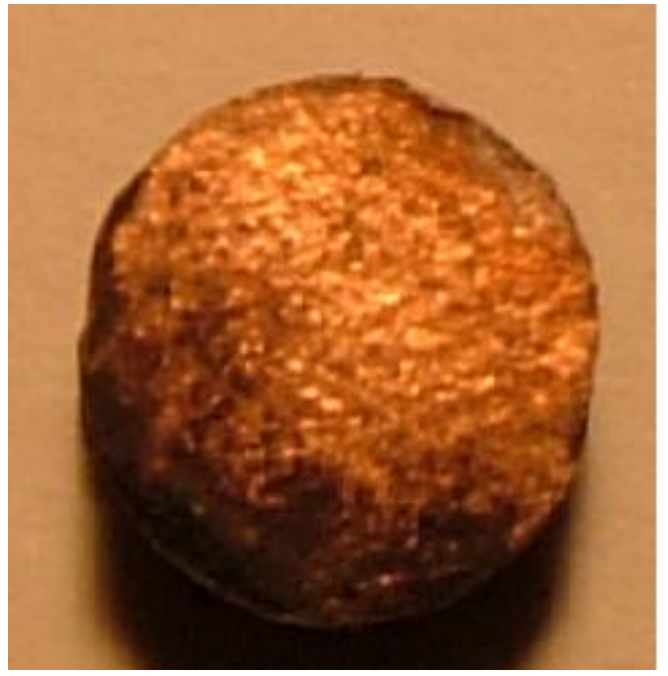

(a)

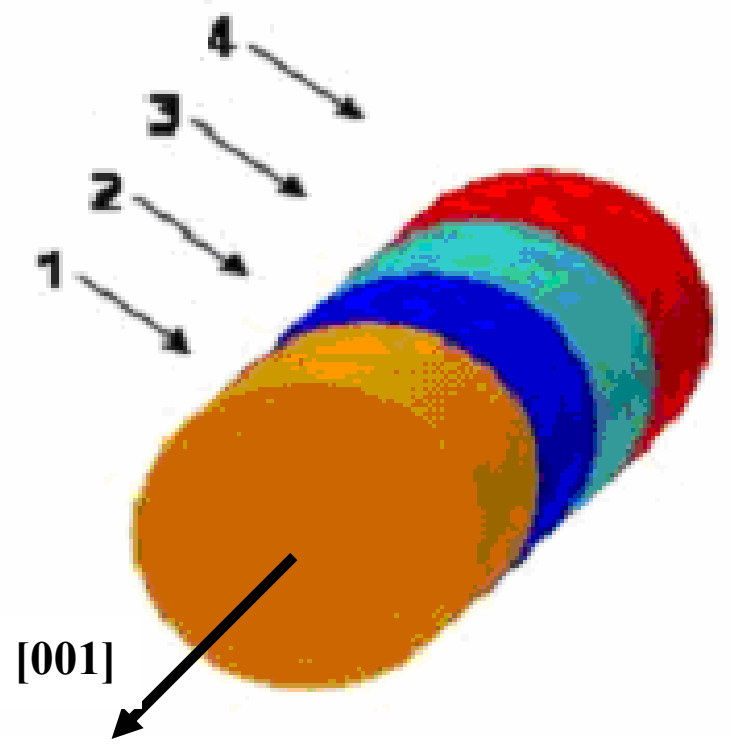

(b)

Figure 4: (a) As-received sample (b) Slices cut from cylindrical specimen by EDM. 


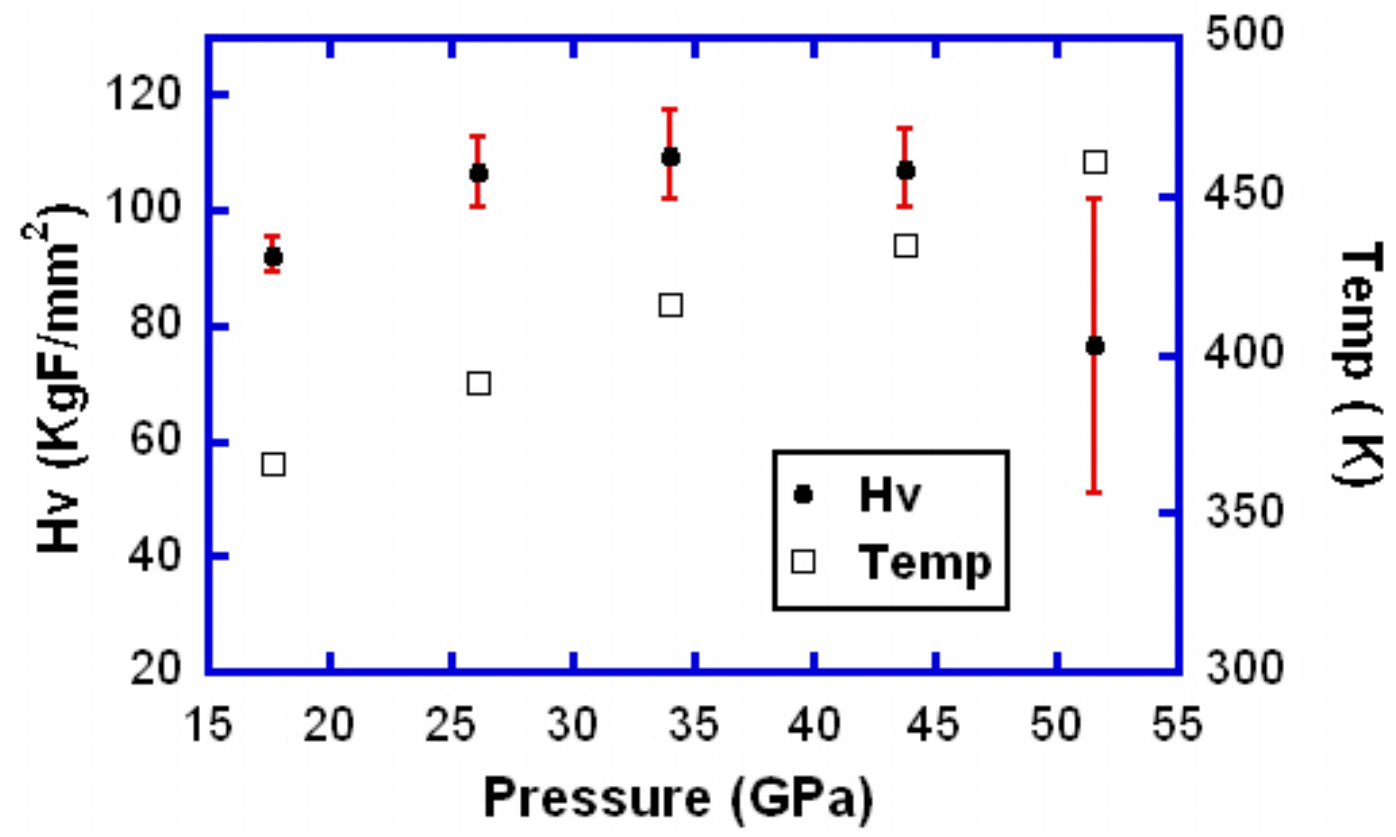

Figure 5: Hardness and Temperature Vs. Peak Pressure. 


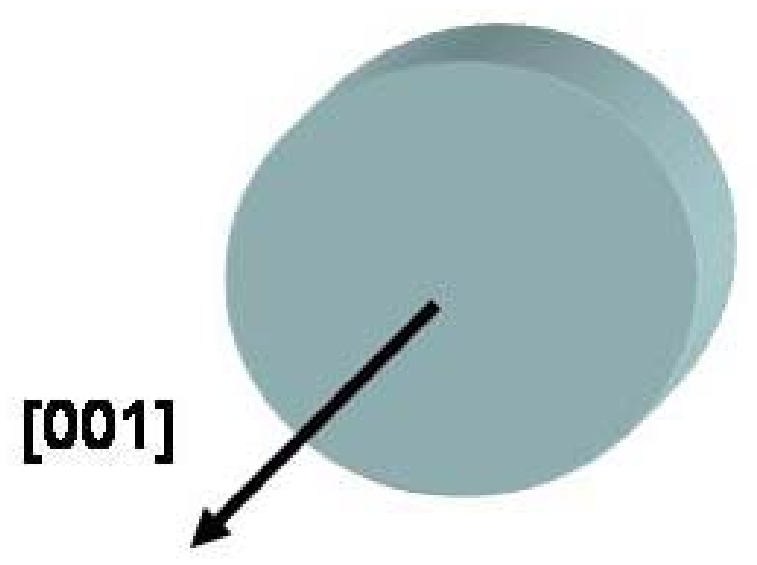

(a)

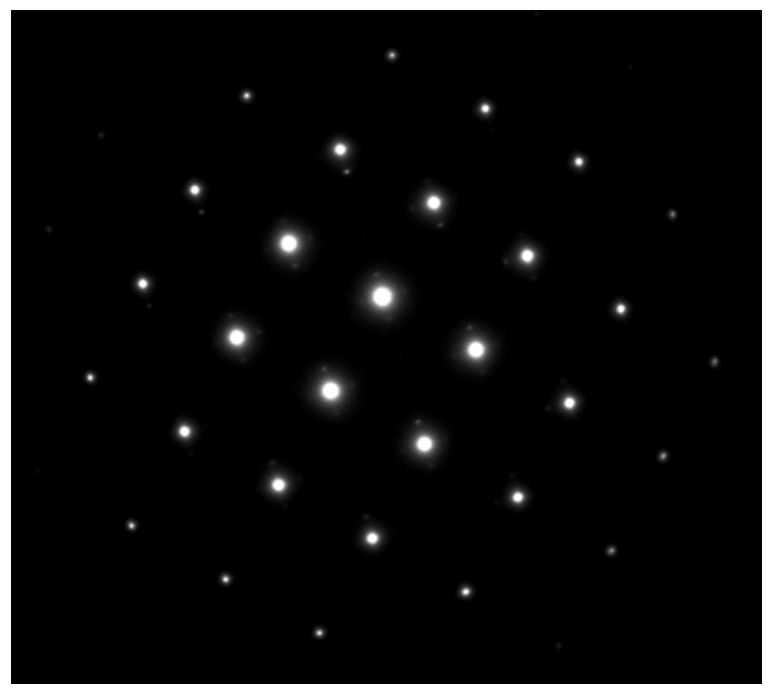

(b)

Figure 6: (a) [001] orientation of all samples. (b) Typical diffraction pattern of samples indicating the [001] orientation. 


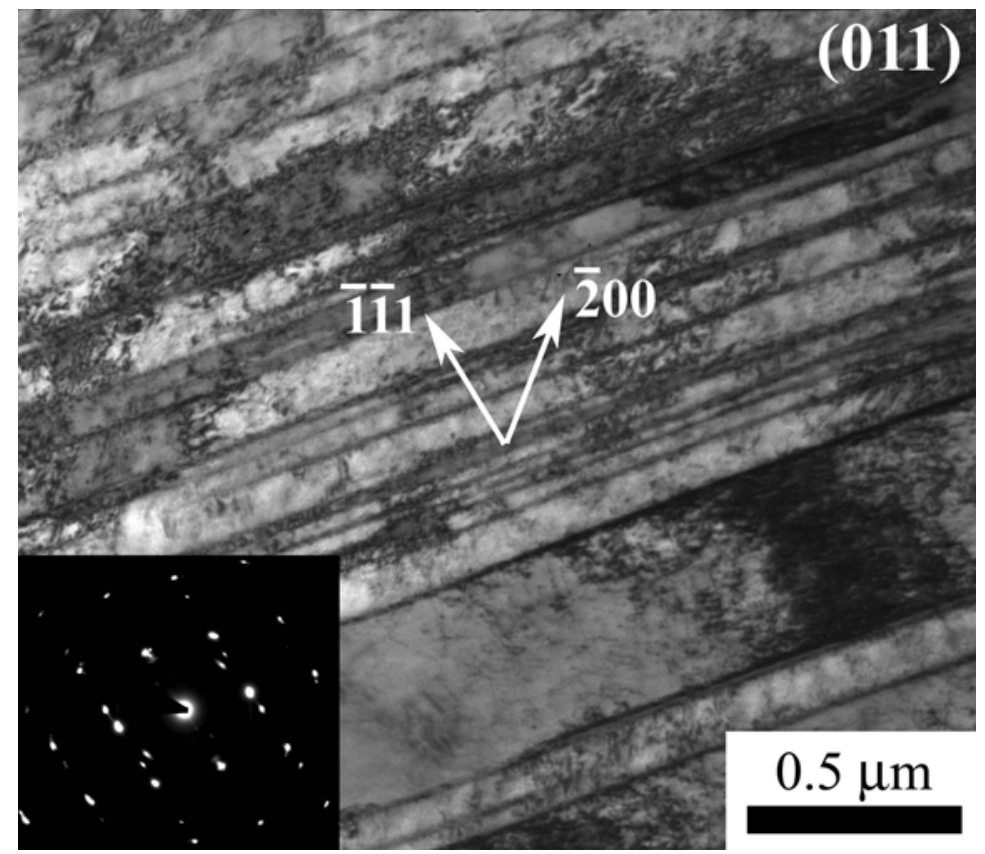

(a)

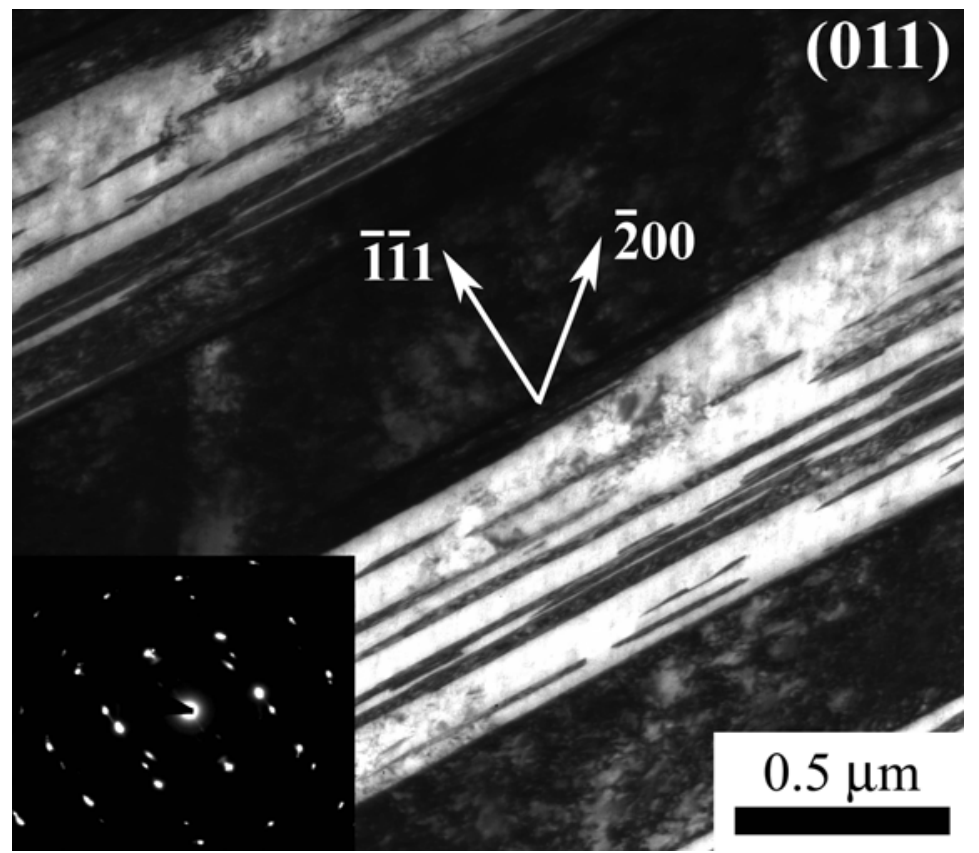

(b)

Figure 7: (a) Twinned regions at $\sim 0.1 \mathrm{~mm}$ from the surface (experiment $\mathbf{A}$ ); (b) Twinned regions at $\sim 0.1 \mathrm{~mm}$ from the surface (experiment $\mathbf{A}$ ) $-52 \mathrm{GPa}$. 


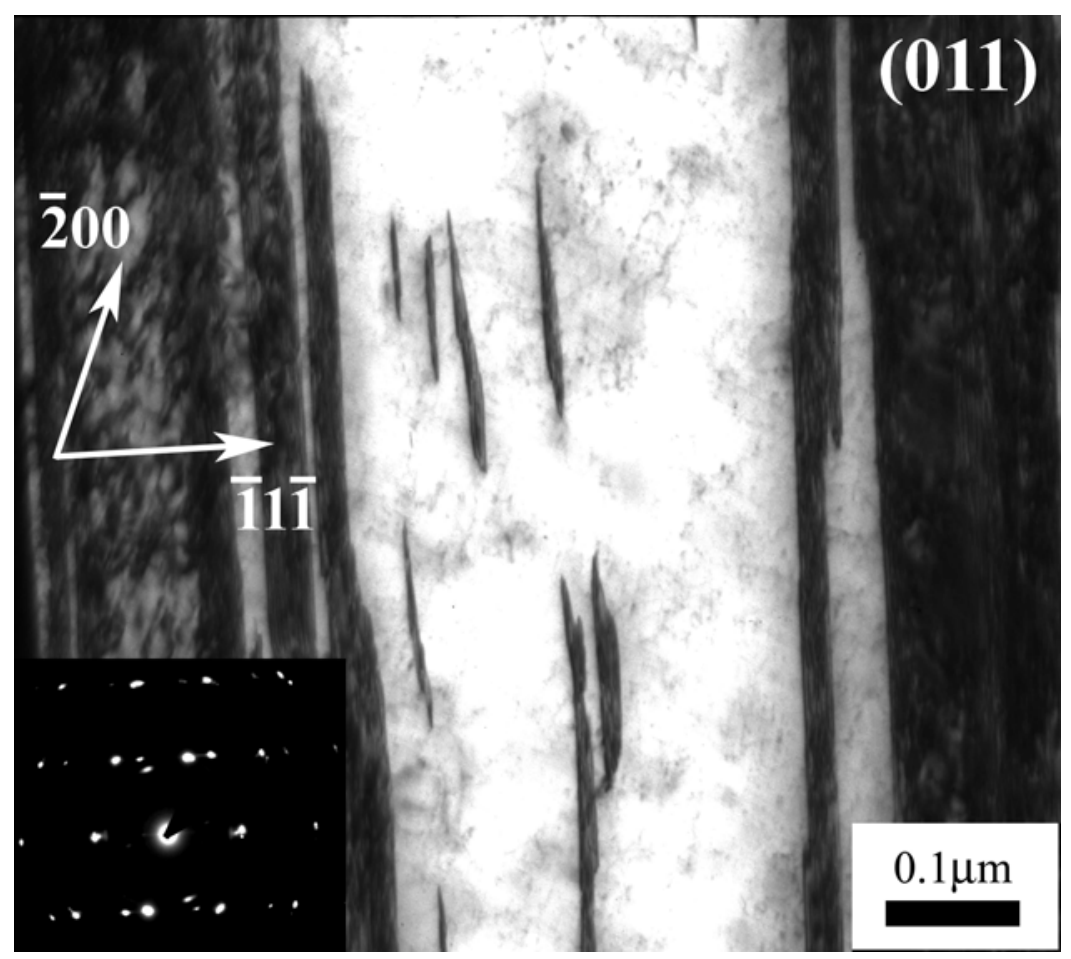

Figure 8: Highly magnified view of micro-twins elongated along [200] direction. 


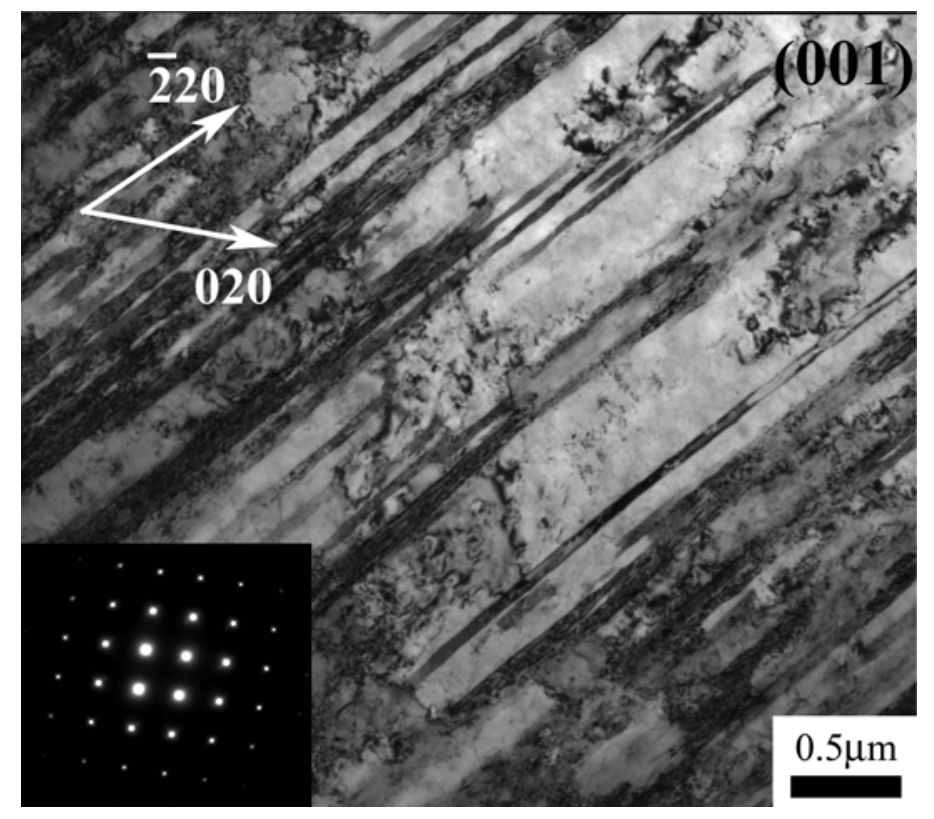

(a)

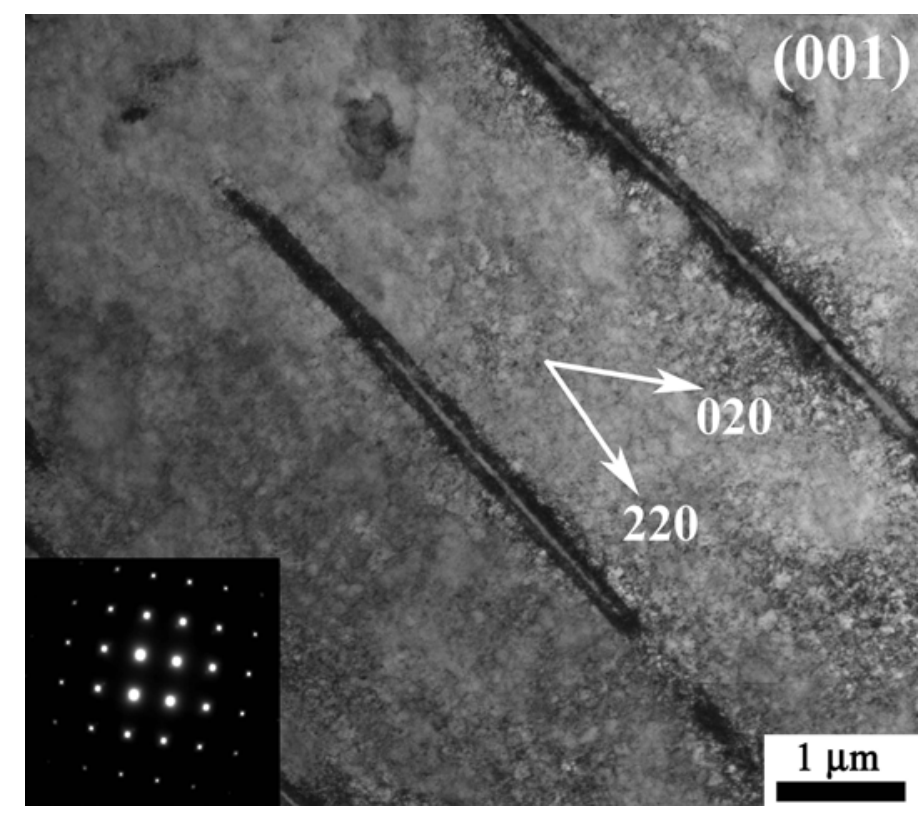

(b)

Figure 9: (a) Stacking faults at $0.1 \mathrm{~mm}$ from surface running along [ $\overline{2} 20]$; (b) Stacking faults at $0.1 \mathrm{~mm}$ running along [220], $52 \mathrm{GPa}$. 


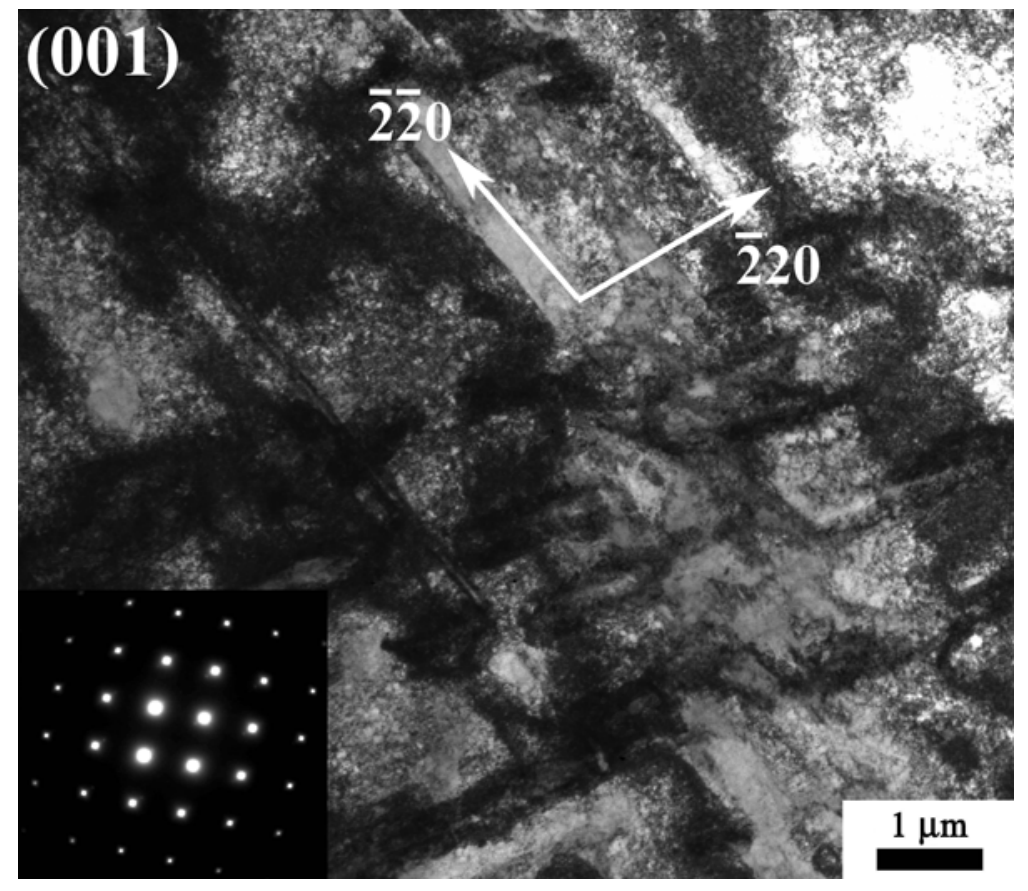

Figure 10: Two Stacking fault variants running along $[\overline{2} 20]$ and $[\overline{2} 20], 52 \mathrm{GPa}$. 


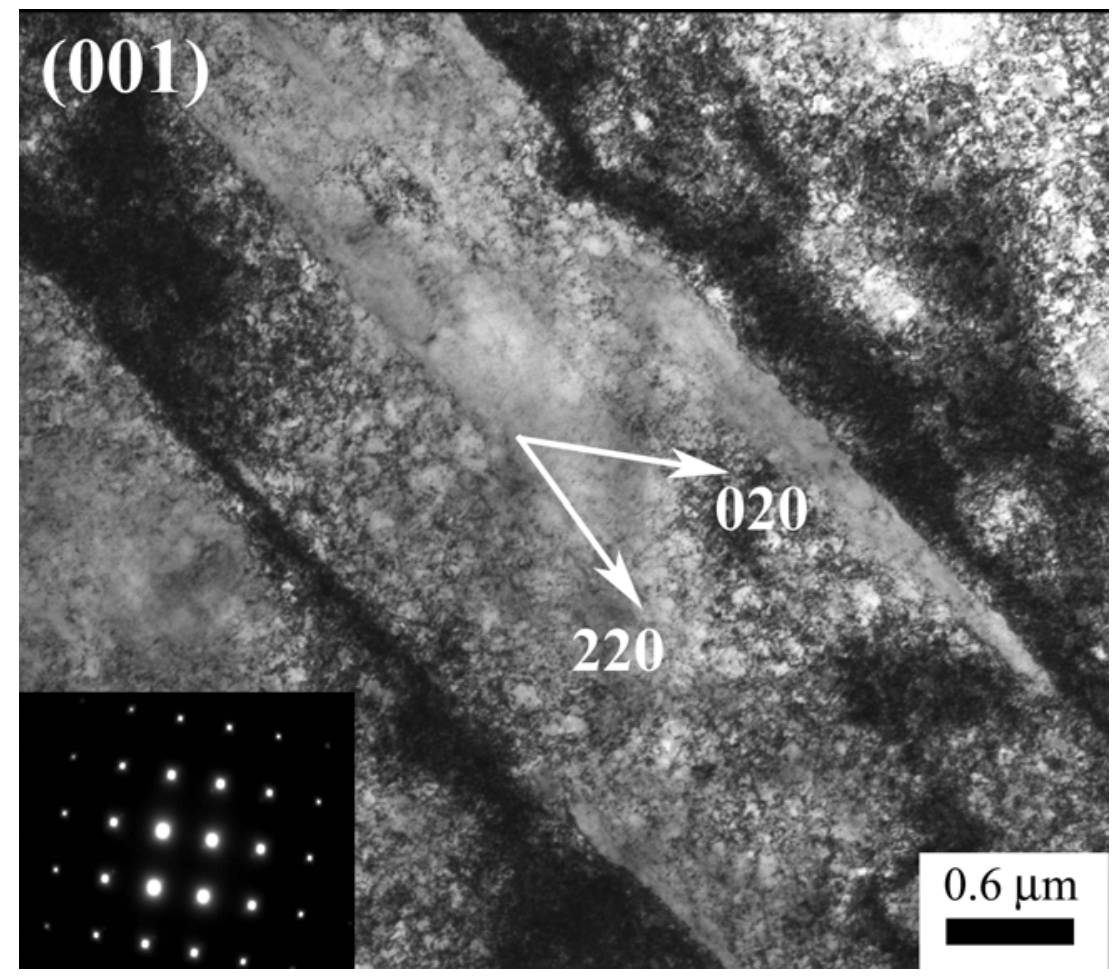

Figure 11: Lath-like features and dislocation activity at $\sim 0.1 \mathrm{~mm}, 52 \mathrm{GPa}$. 


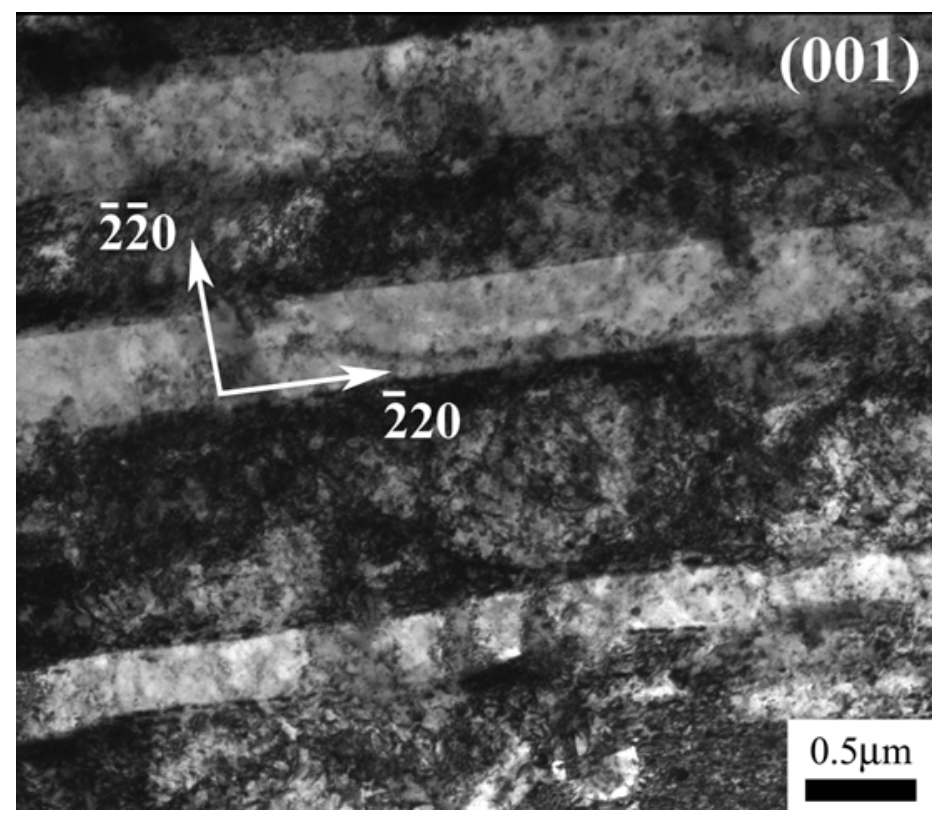

(a)

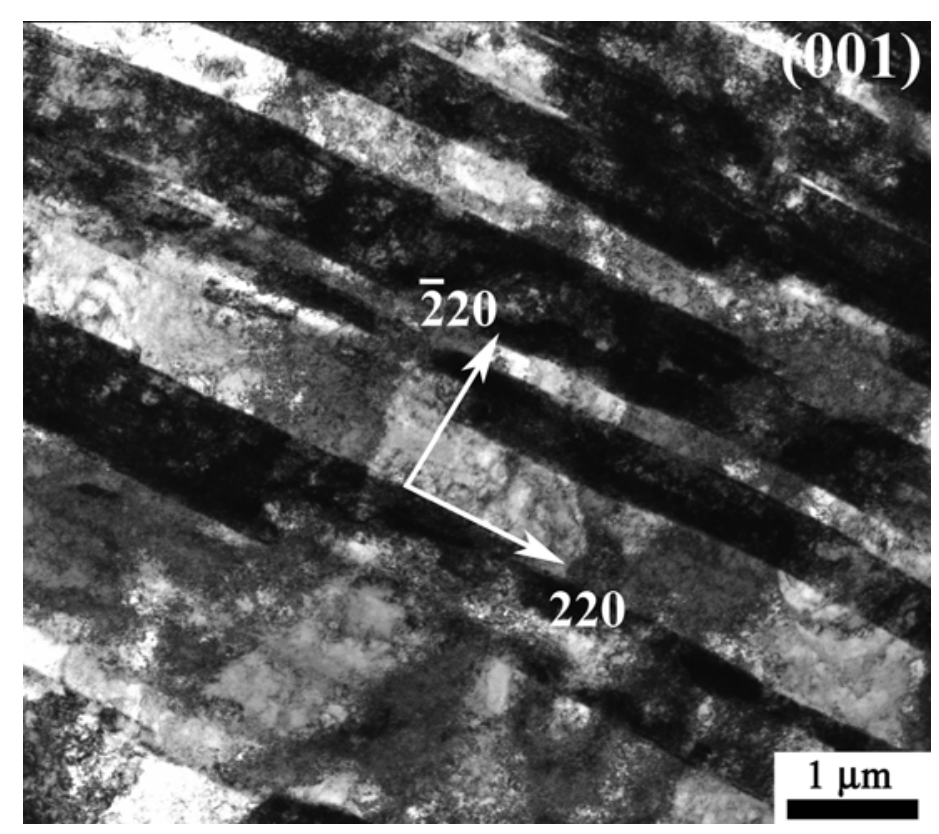

(b)

Figure 12: (a) Heavily dislocated laths at $0.7 \mathrm{~mm}$ running almost perpendicular to the [ $\overline{2} 20]$;

(b) Heavily dislocated laths at $1.2 \mathrm{~mm}$ running along [220] - $52 \mathrm{GPa}$. 


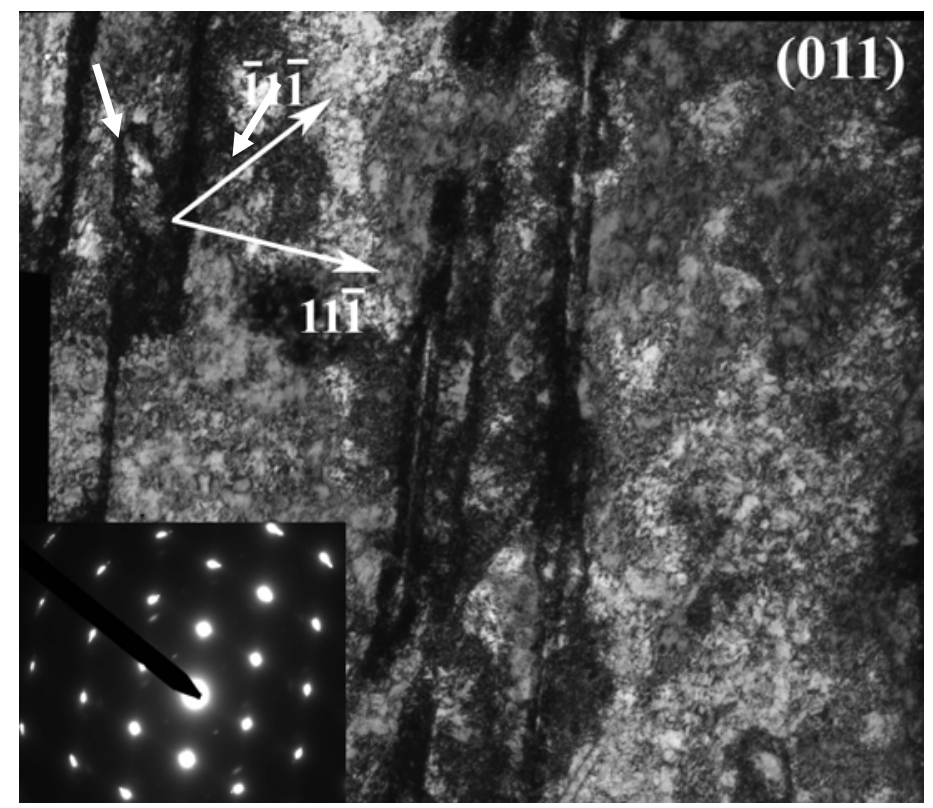

(a)

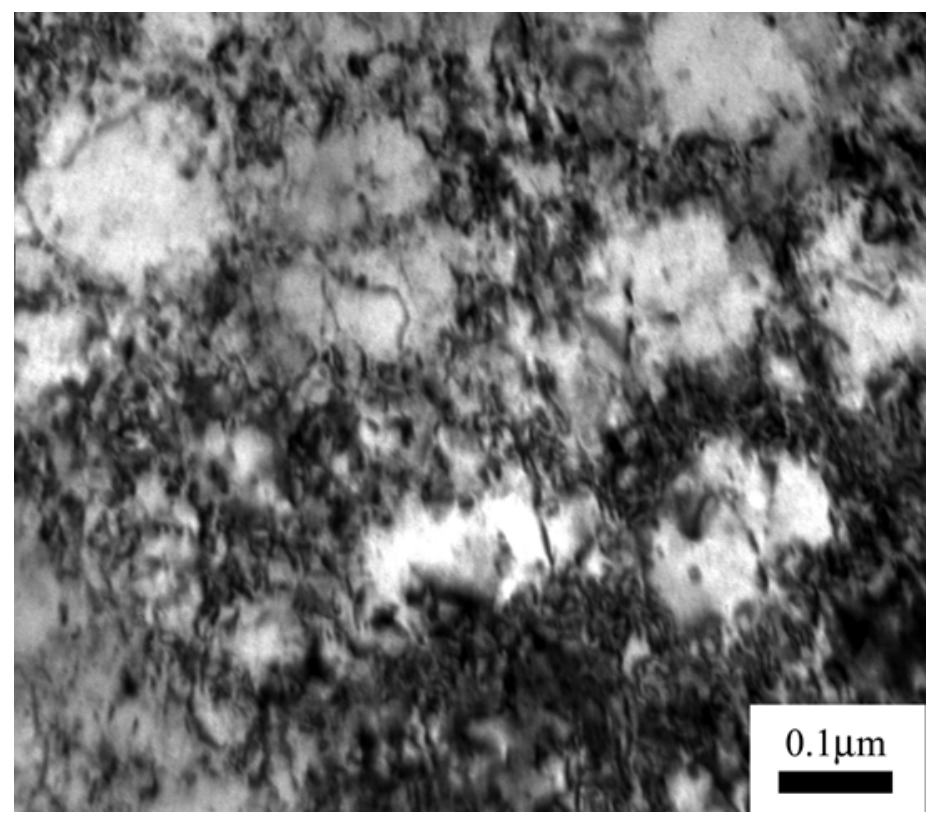

(b)

Figure 13: (a) Dislocation activity and twinning at $1.2 \mathrm{~mm}$ (indicated by the arrows); (b) Dislocation cell formation at $1.2 \mathrm{~mm}$ from surface, average size: $0.15 \mu \mathrm{m}-52 \mathrm{GPa}$. 


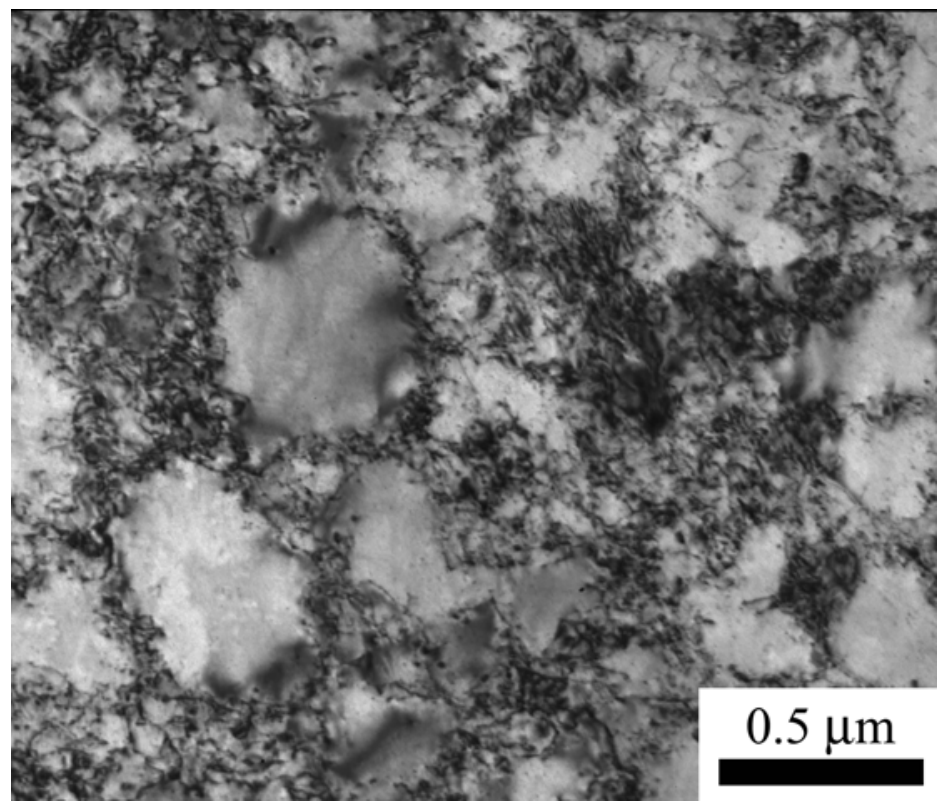

(a)

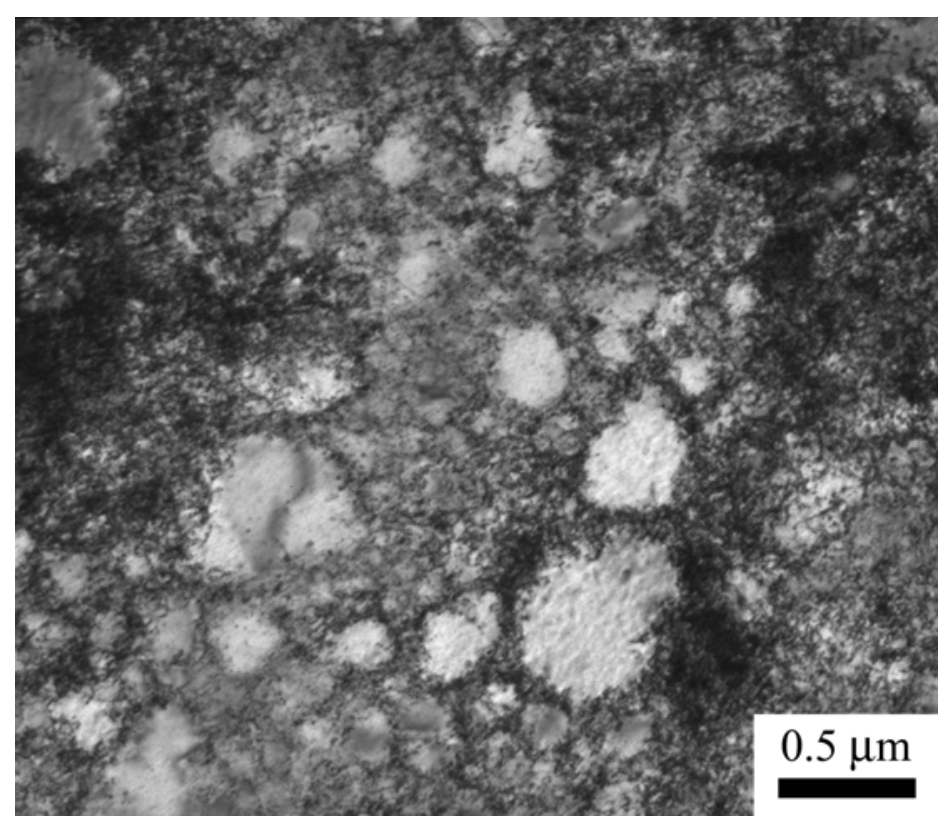

(b)

Fig. 14: (a) Dislocation cells at $0.15 \mathrm{~mm}$, average cell size: $0.36 \mu \mathrm{m}$; Dislocation cells at $2 \mathrm{~mm}$, average cell size: $0.43 \mu \mathrm{m}, 44 \mathrm{GPa}$. 


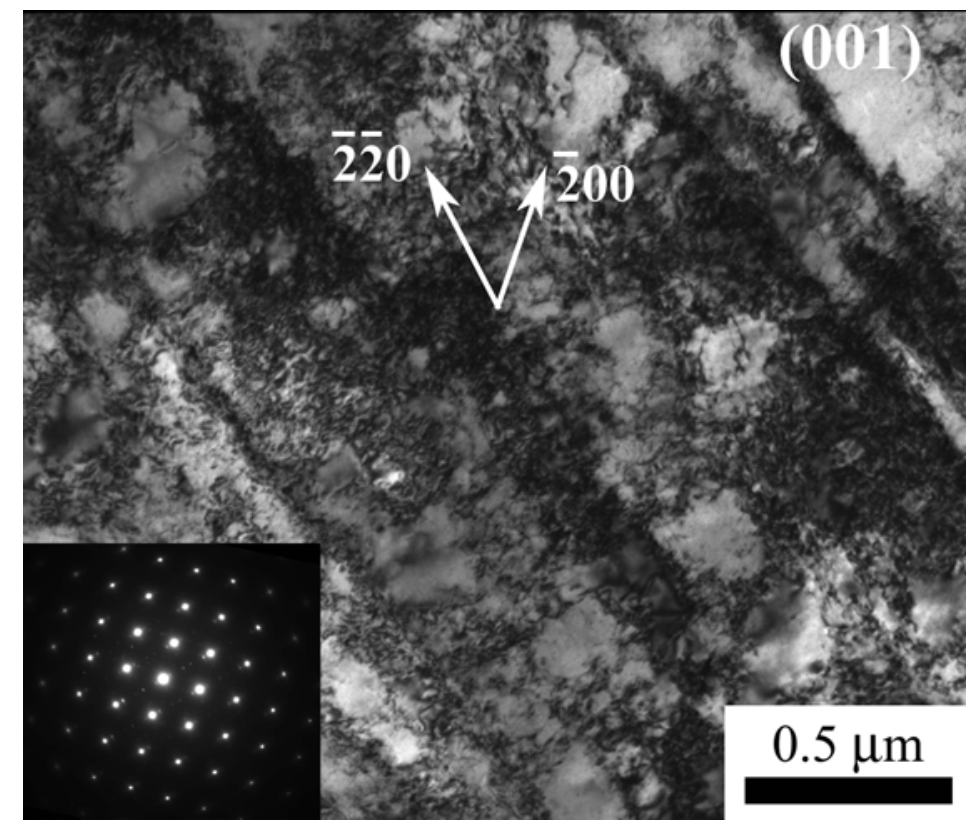

Figure 15: Dislocated laths and cells at $0.15 \mathrm{~mm}$ from surface, $44 \mathrm{GPa}$. 


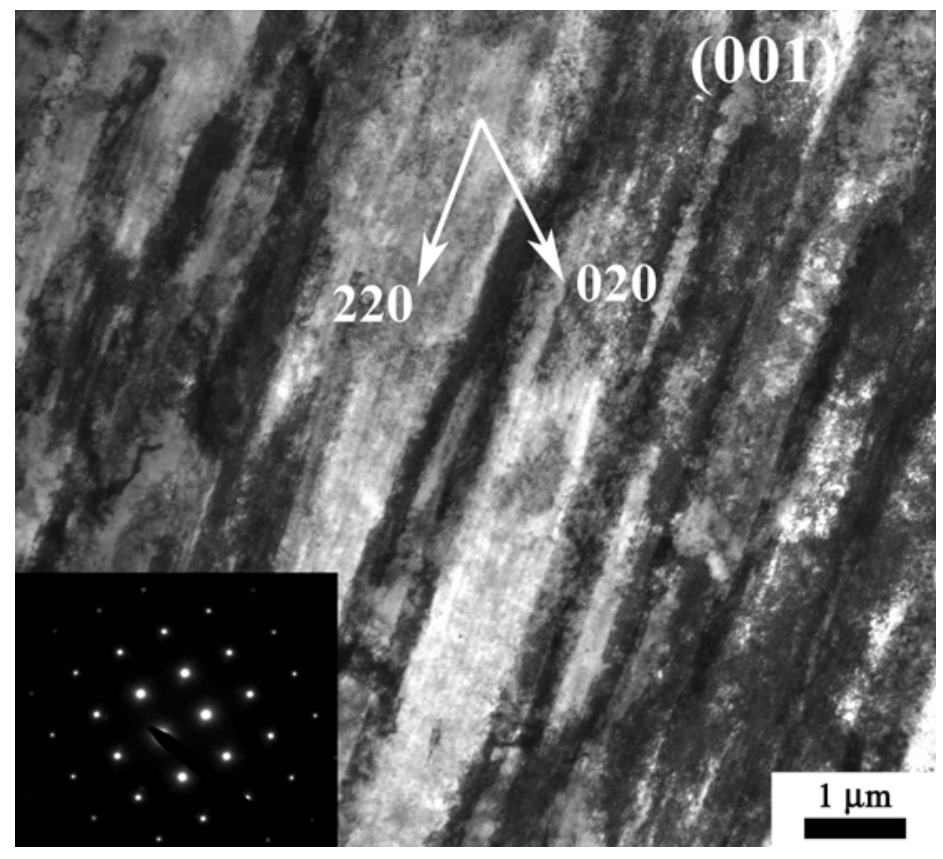

(a)

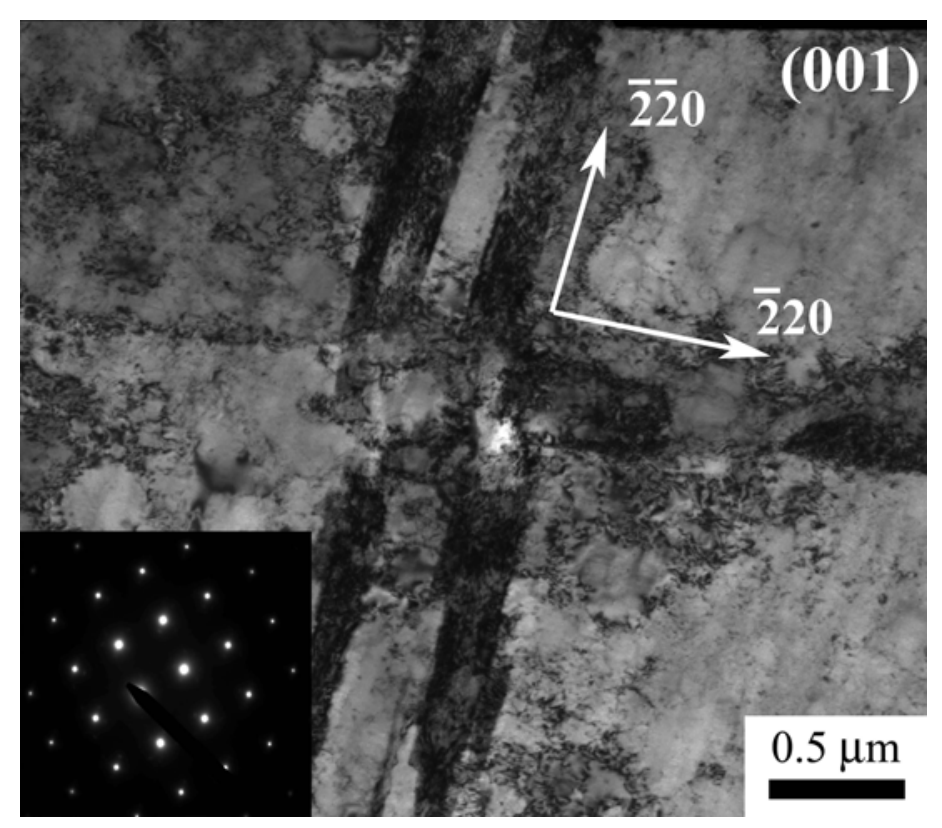

(b)

Figure 16: (a) Dislocated laths at $0.15 \mathrm{~mm}$; (b) Intersecting laths at $0.15 \mathrm{~mm}-44 \mathrm{GPa}$. 


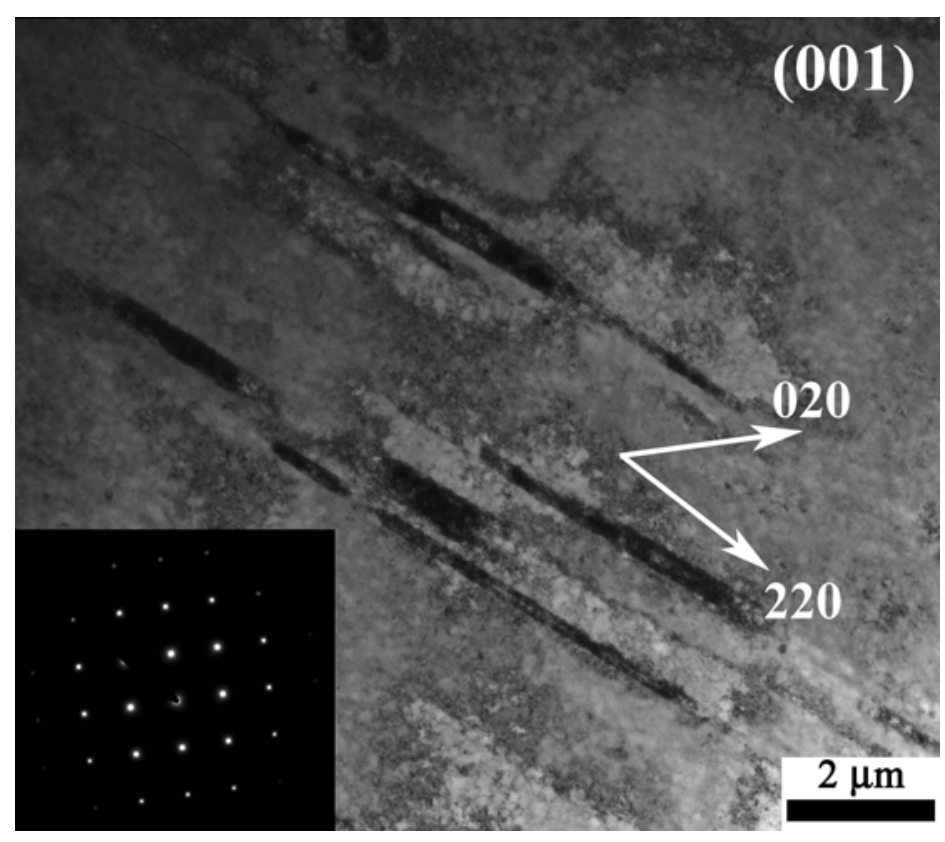

(a)

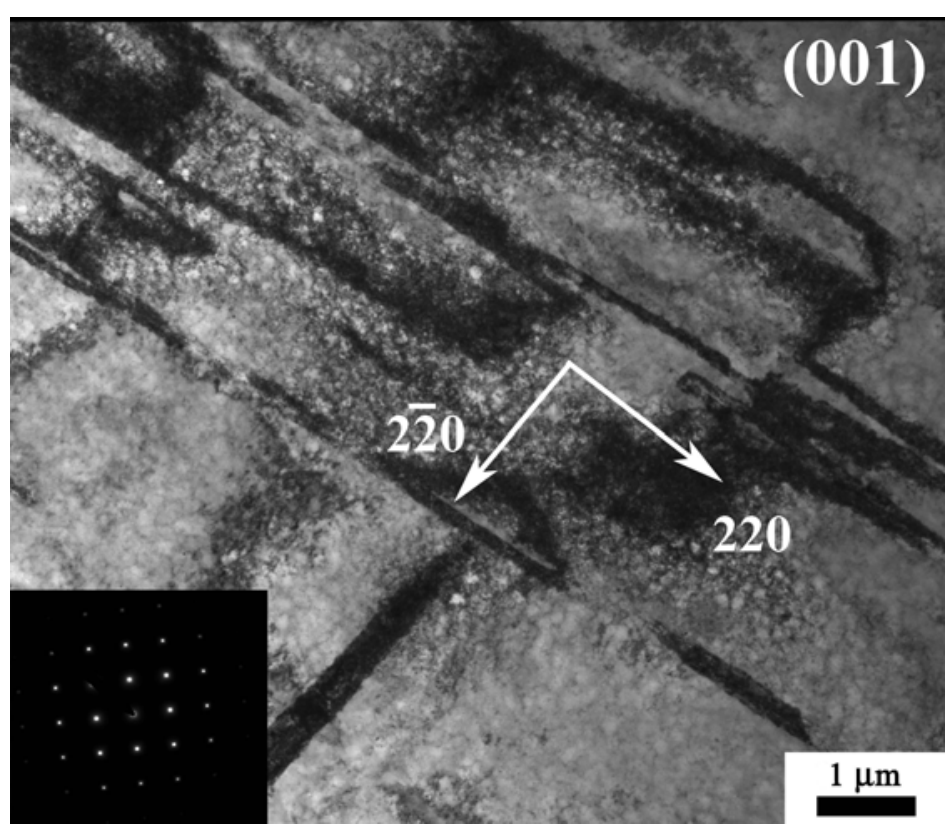

(b)

Figure 17: (a) Dislocated laths at $0.6 \mathrm{~mm}$ from impact surface; (b) Intersecting laths, 34 GPa. 


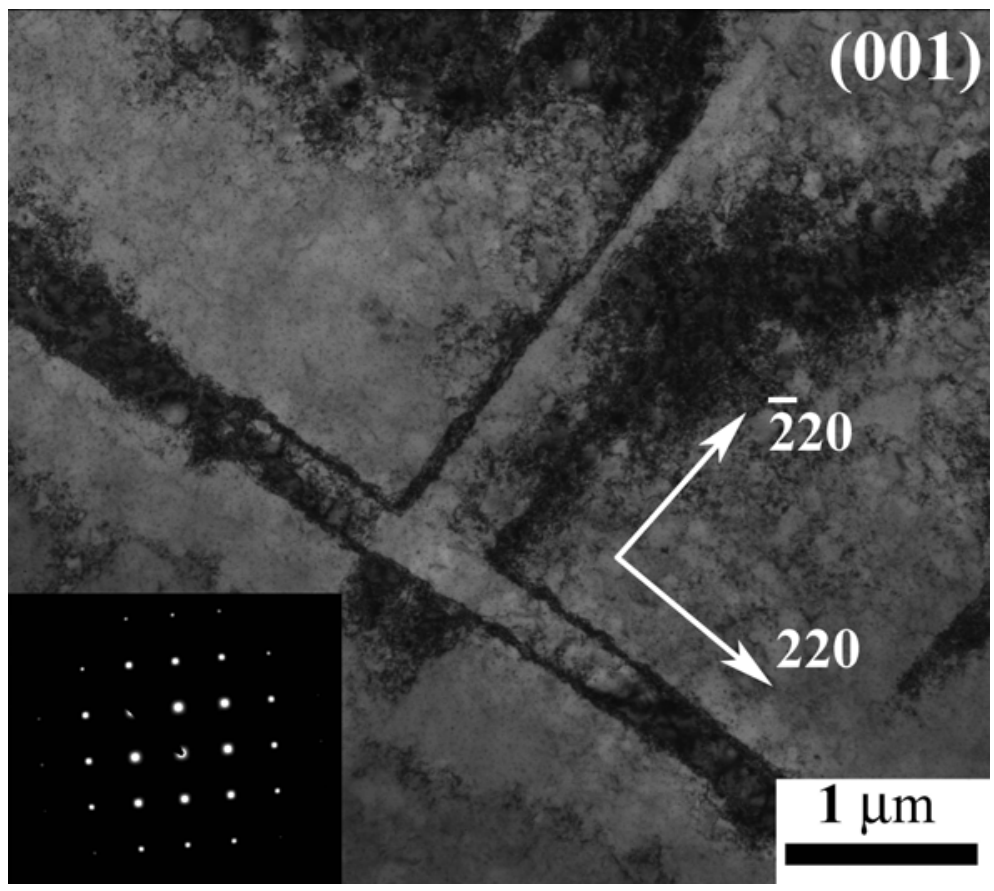

Figure 18: Intersecting laths at $1.05 \mathrm{~mm}$ from surface (34 GPa). 


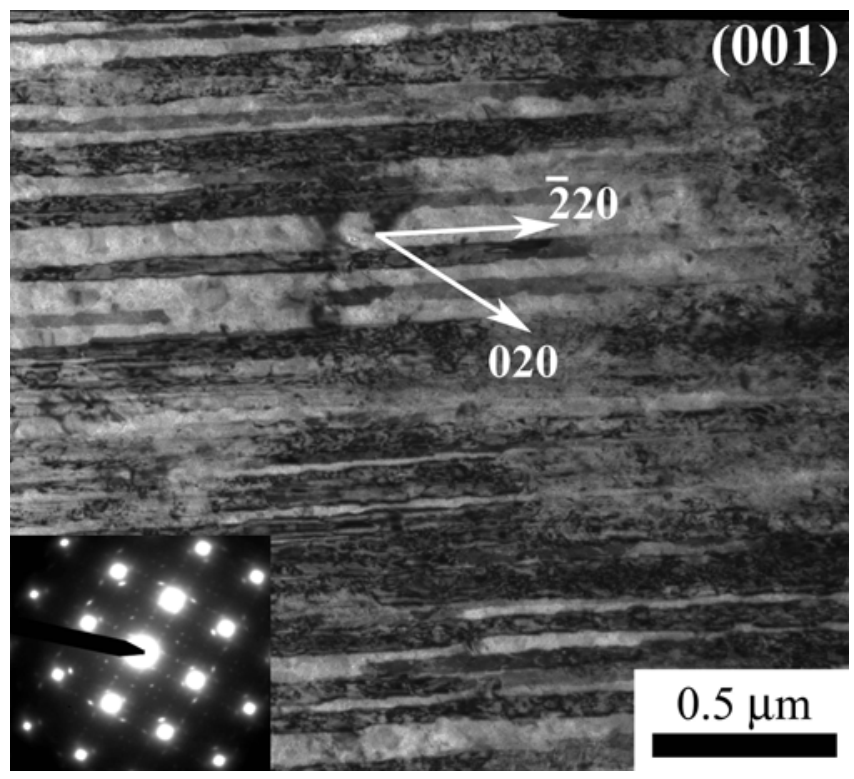

(a)

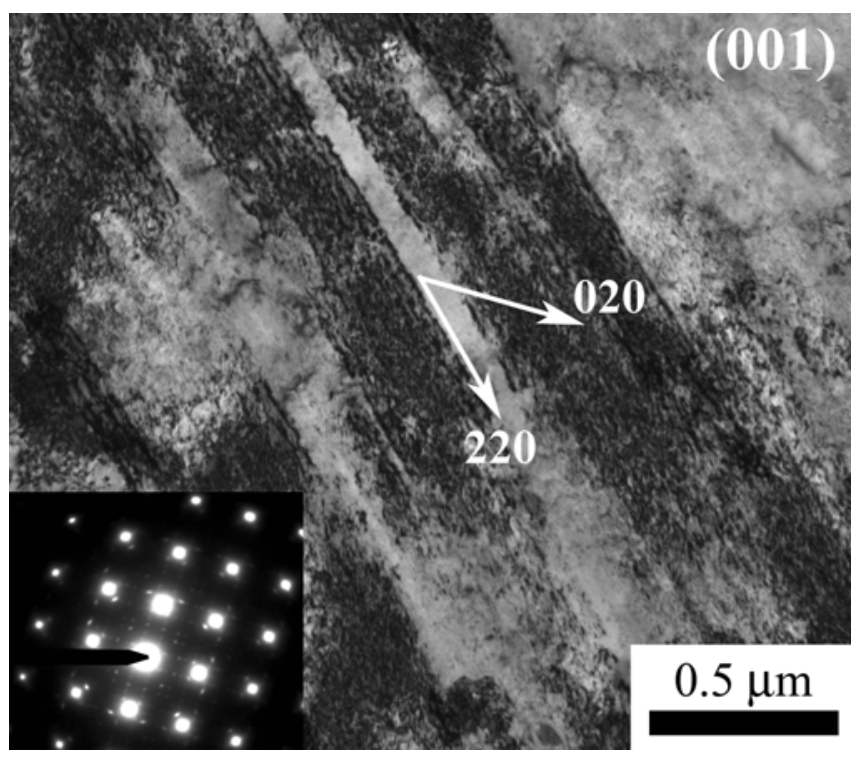

(b)

Figure 19: A region of stacking faults along $[\overline{2} 20]$ at $0.9 \mathrm{~mm}$ from the surface; (b) stacking faults along [220] at 1.3mm from the surface, 26.1 GPa. 


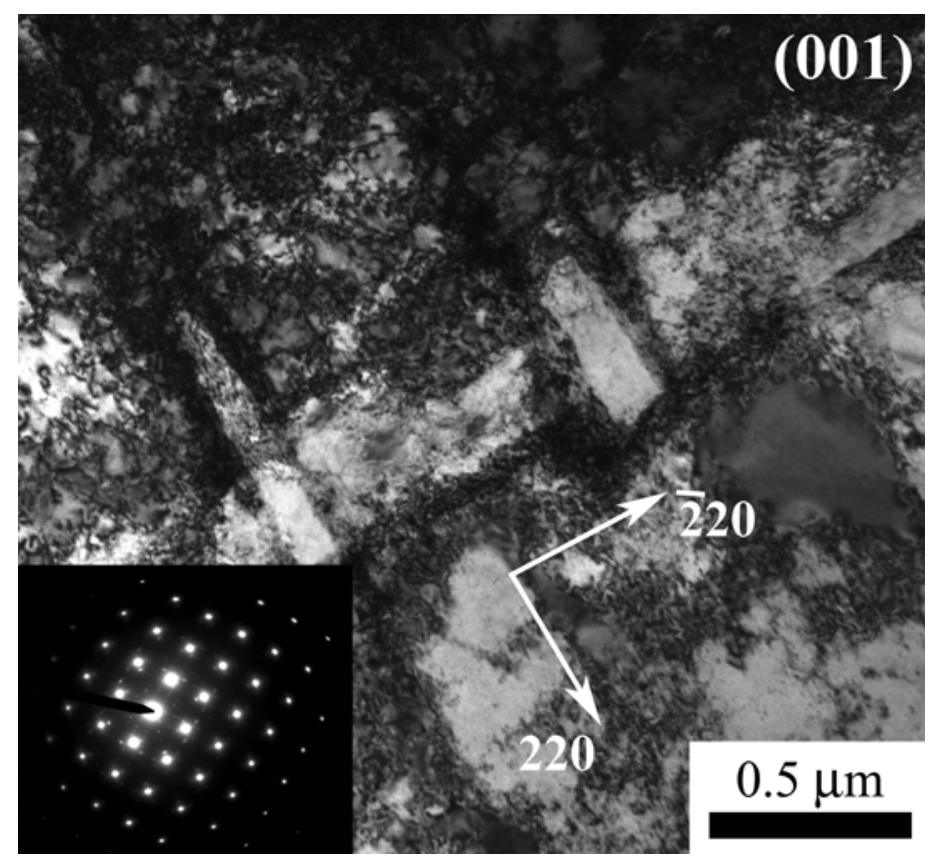

(a)

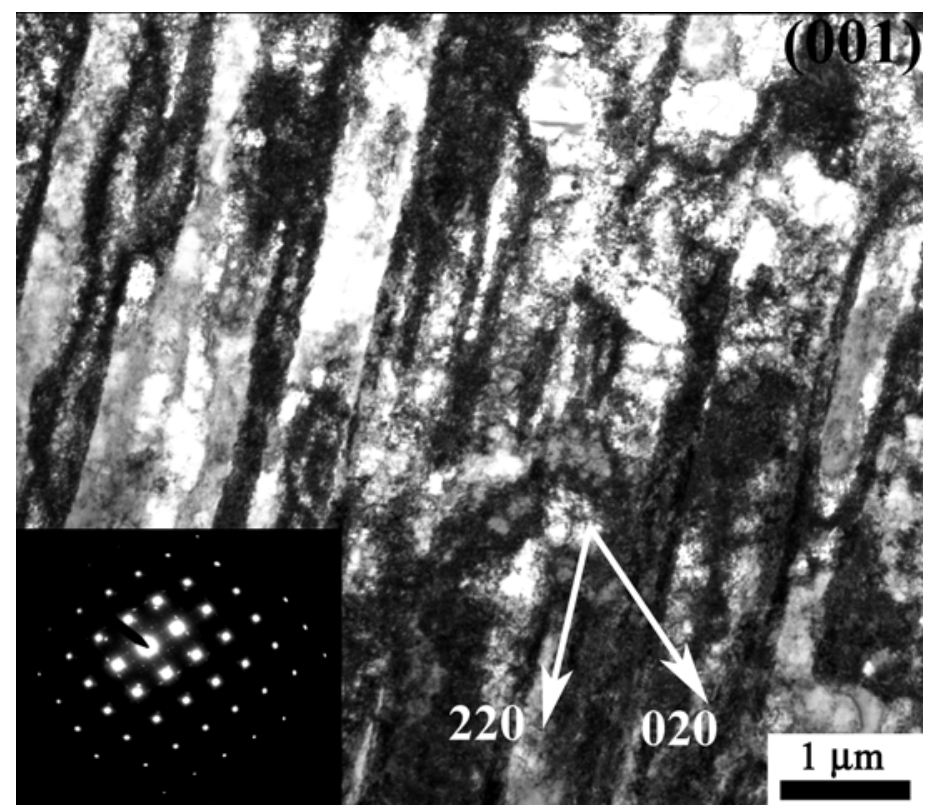

(b)

Figure 20: (a) Intersecting laths at $1.3 \mathrm{~mm}$ from impact surface; (b) Dislocated laths and some elongated cells at $2.3 \mathrm{~mm}$ from the surface $(26.1 \mathrm{GPa})$. 


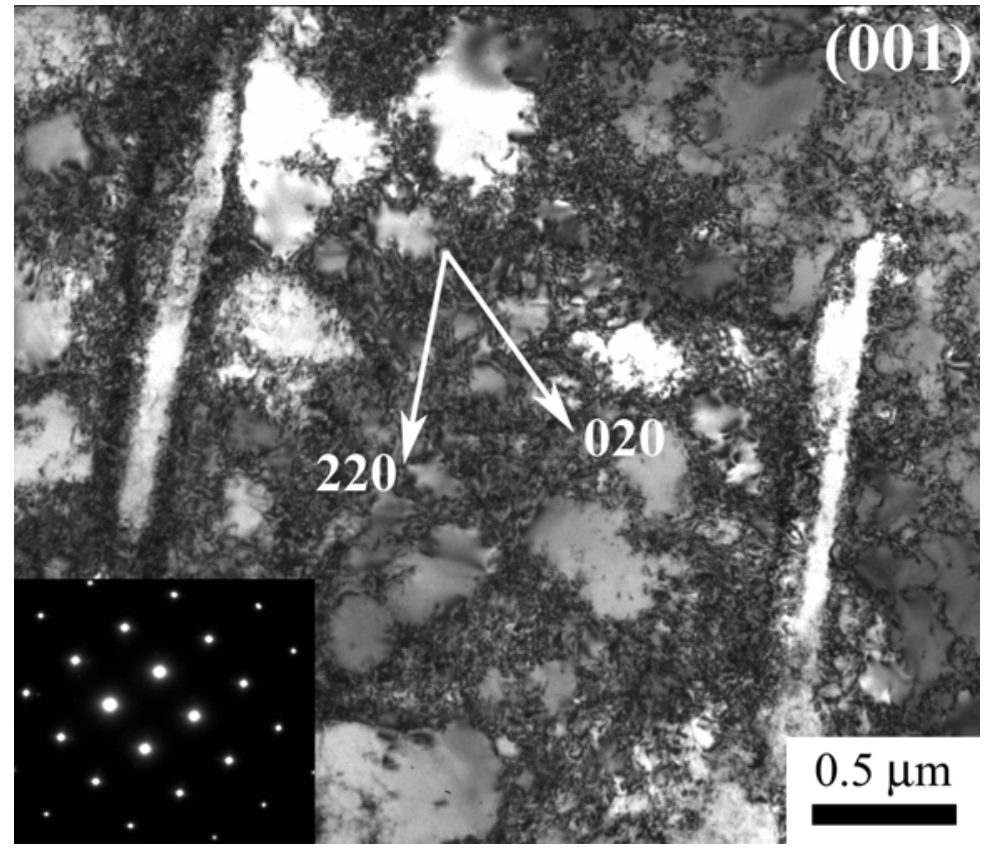

Figure 21: Dislocation cells and laths/elongated cells at $0.13 \mathrm{~mm}$ from the surface $-18 \mathrm{GPa}$; B close to [001]. 


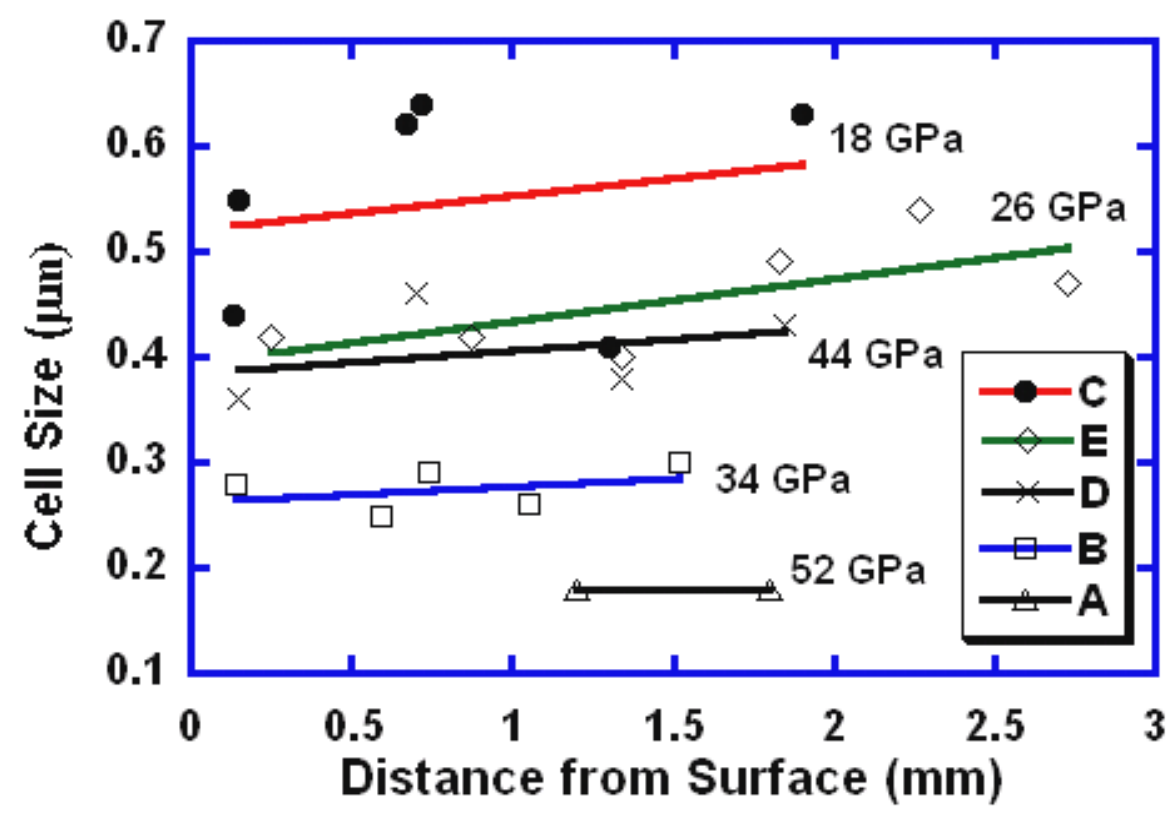

(a)

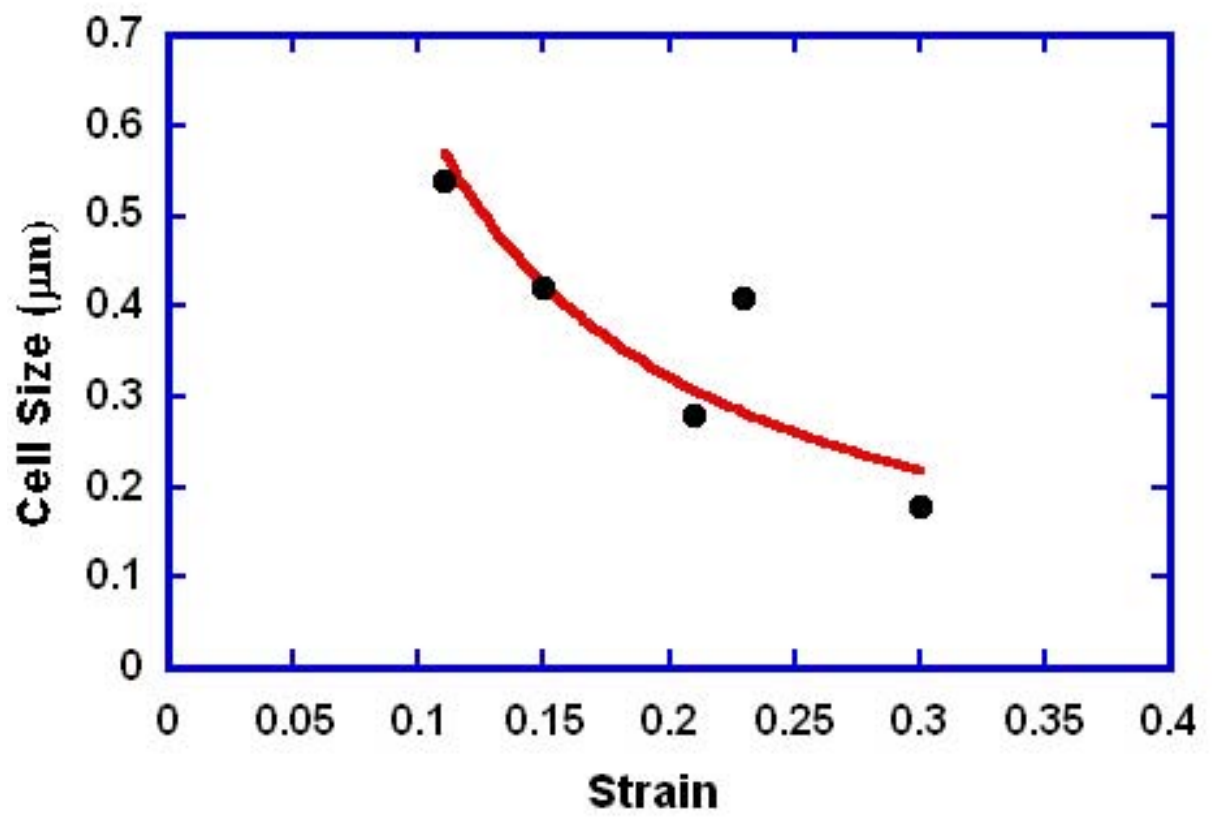

(b)

Figure 22: (a) Cell Size vs. Distance from Surface for all pressure conditions; (b) Cell-Size Vs. Strain for all pressure conditions. 


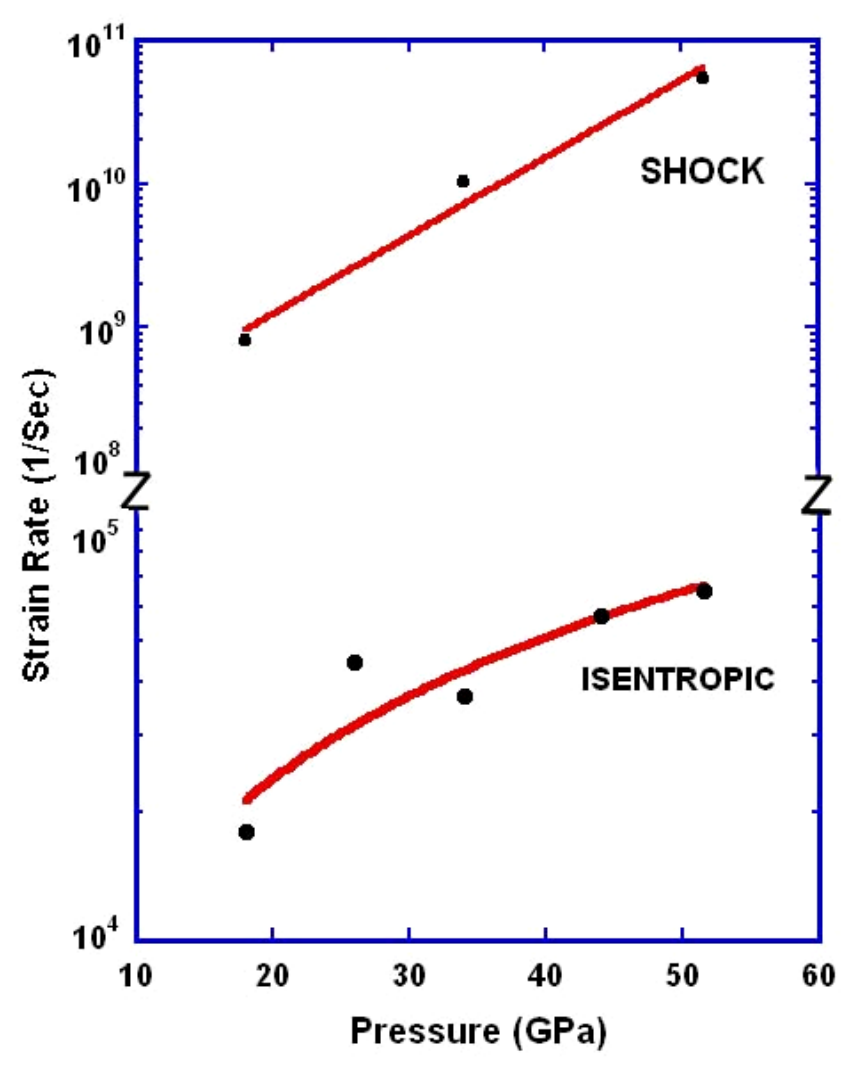

(a)

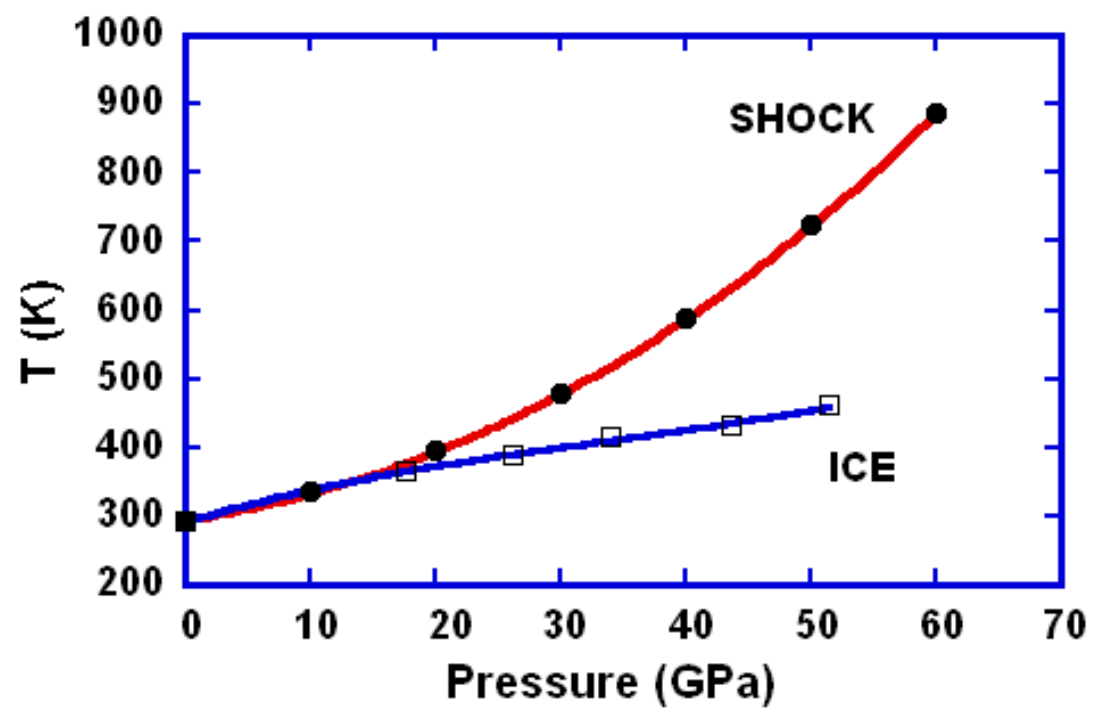

(b)

Fig. 23: (a) Comparison of the strain rate regimes attained in shock and ICE; (b) Comparison of the temperature rise in shock and ICE 


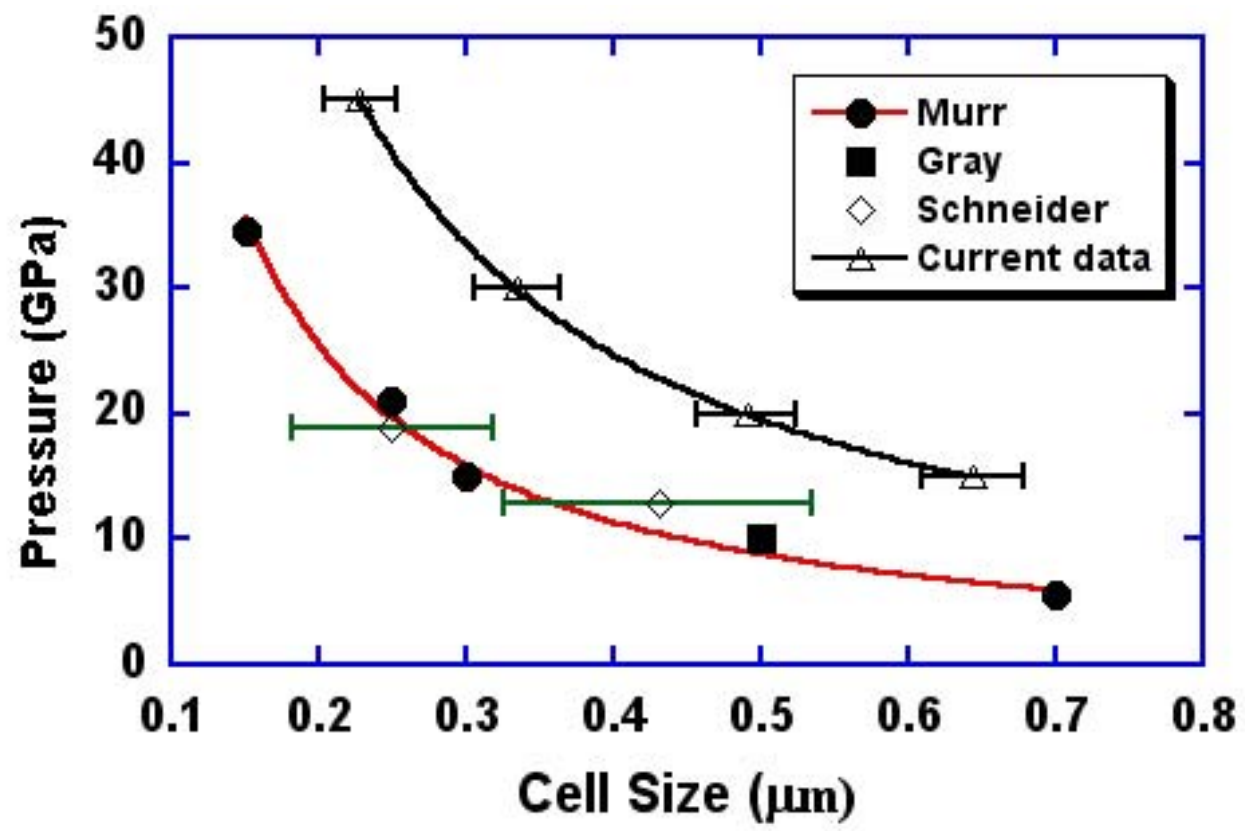

Figure 24: Comparison of cell sizes at different pressures: ICE, laser-shock and flyer-plate impact. 


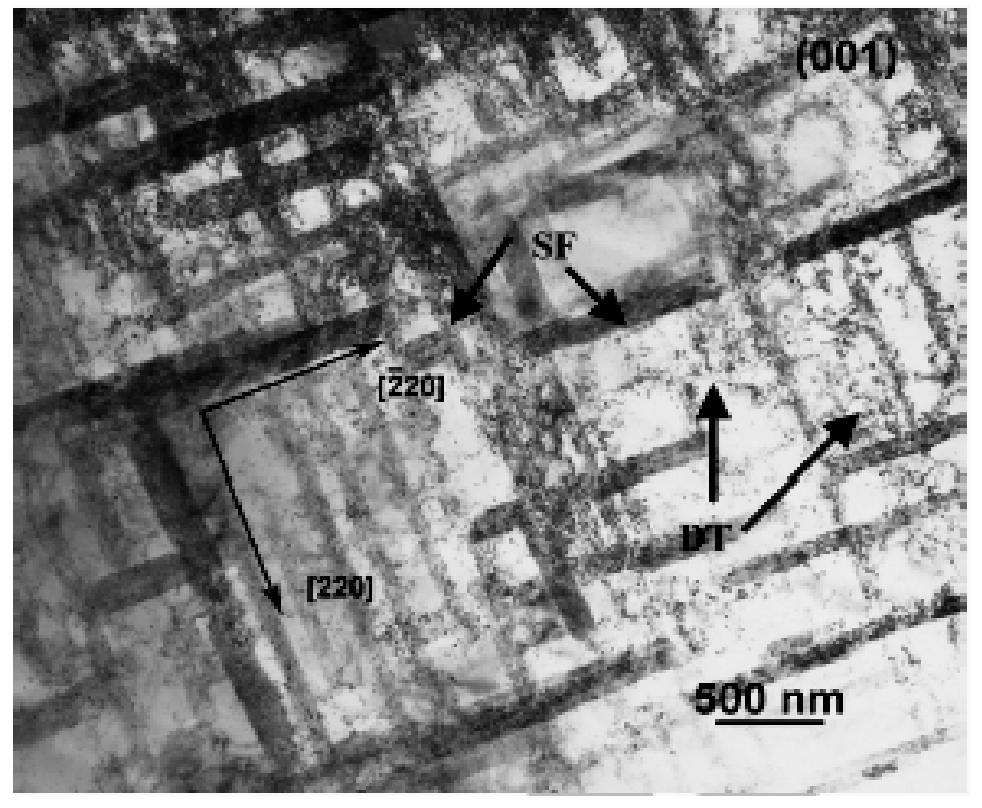

(a)

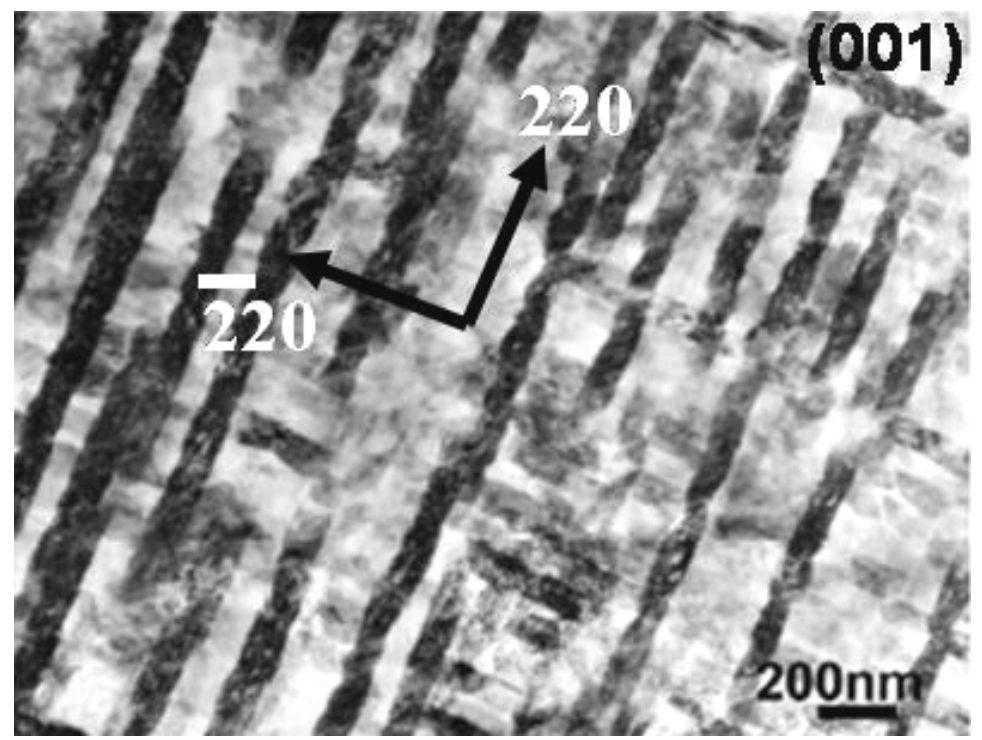

(b)

Figure 25: (a) Stacking faults at $40 \mathrm{GPa}$ in laser-shocked sample; (b) Staking faults at 30 GPa in flyer-plate impacted sample. 


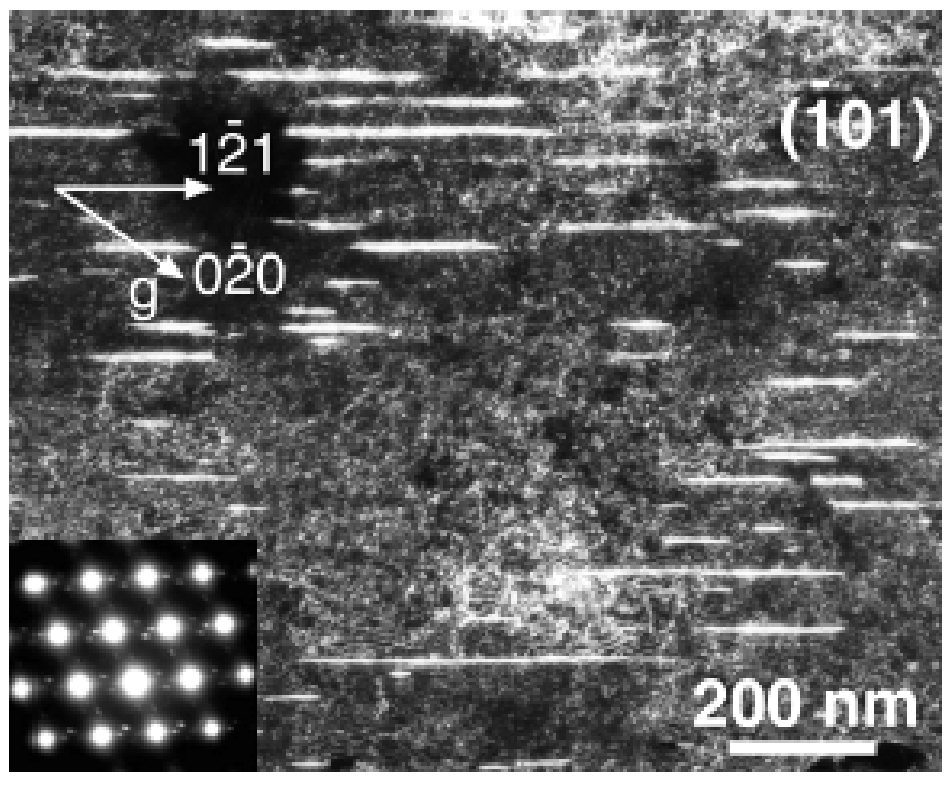

(a)

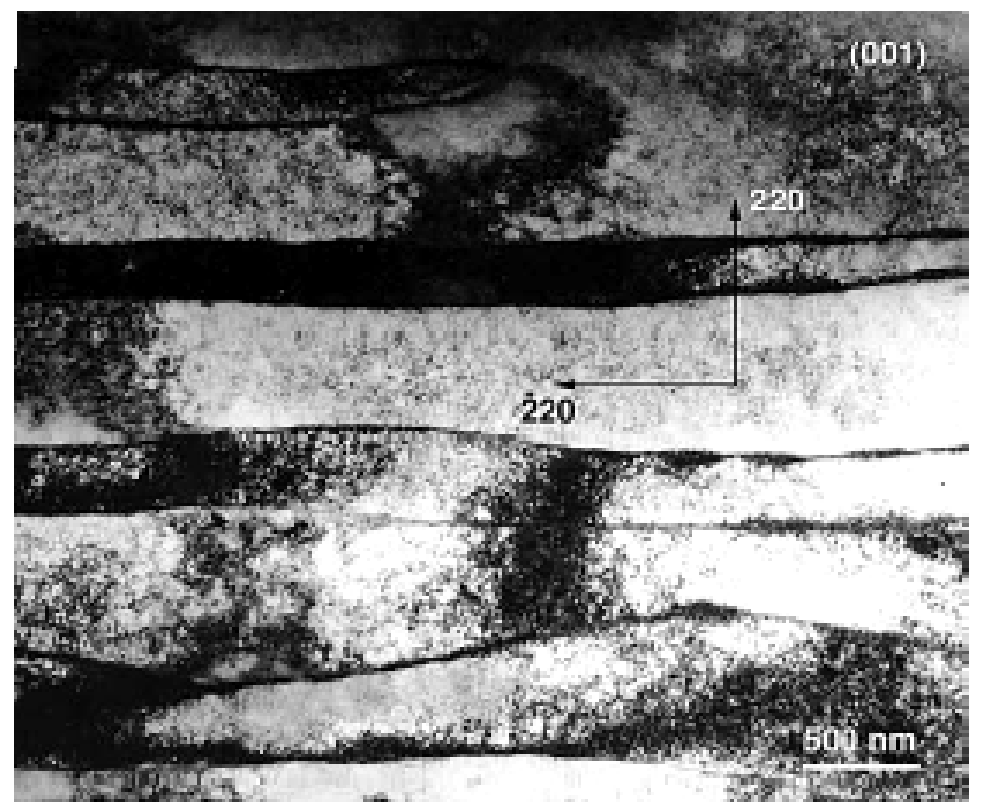

(b)

Figure 26: (a) Micro twins observed in laser shock at $55 \mathrm{GPa}$; (b) Laths observed in laser shock at $55 \mathrm{GPa}$. 


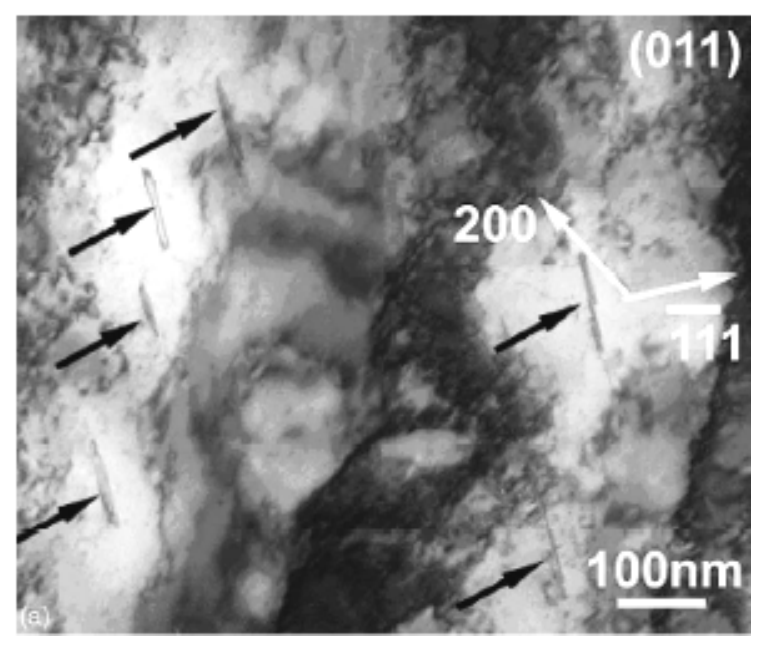

(a)

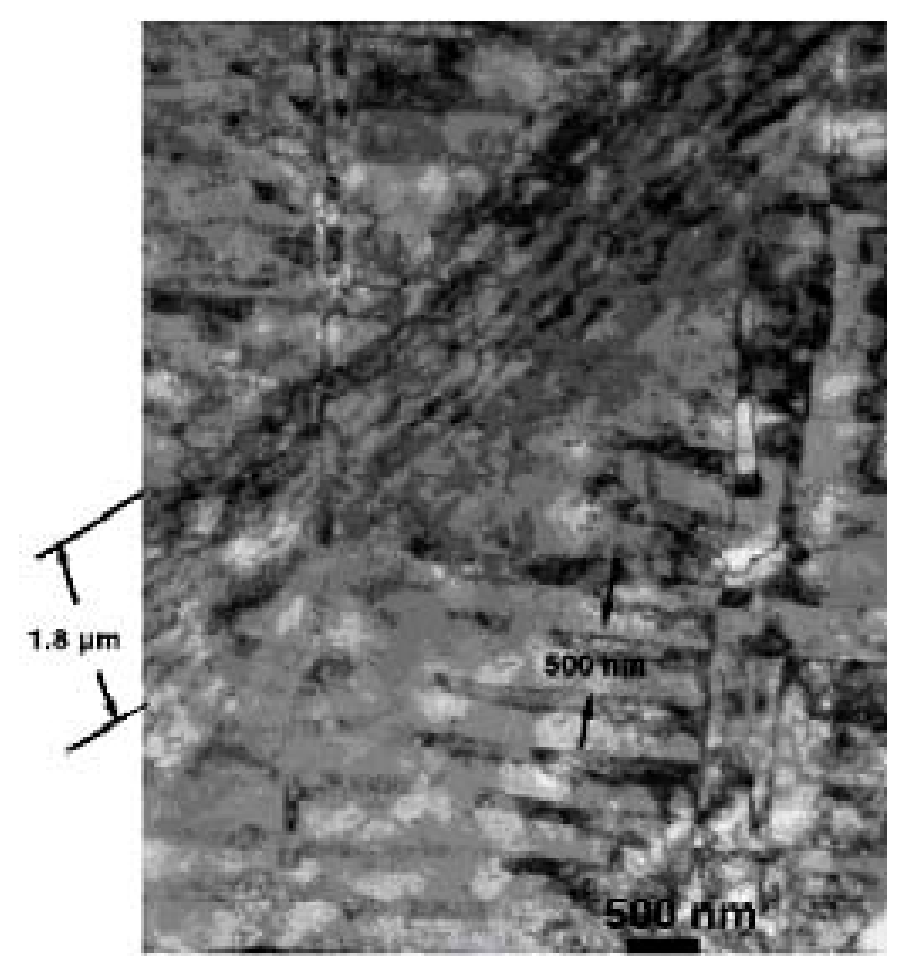

(b)

Figure 27: (a) Micro-twins observed in plate impact at $57 \mathrm{GPa}$; (b) Slip bands and stacking faults observed in plate impact at $57 \mathrm{GPa}$. 


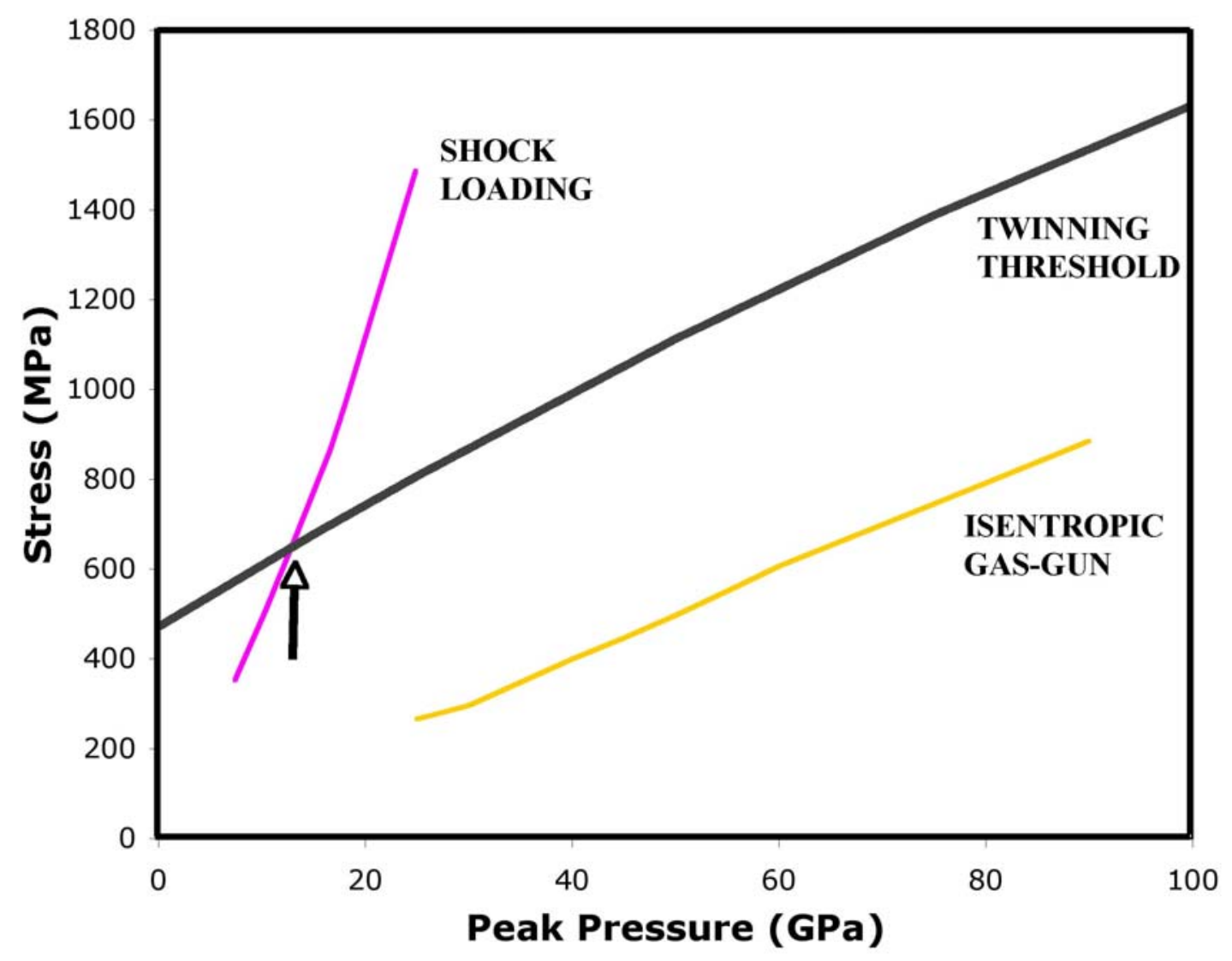

Figure 28: Flow stress of [100] oriented copper vs. peak pressure in shock and ICE. 


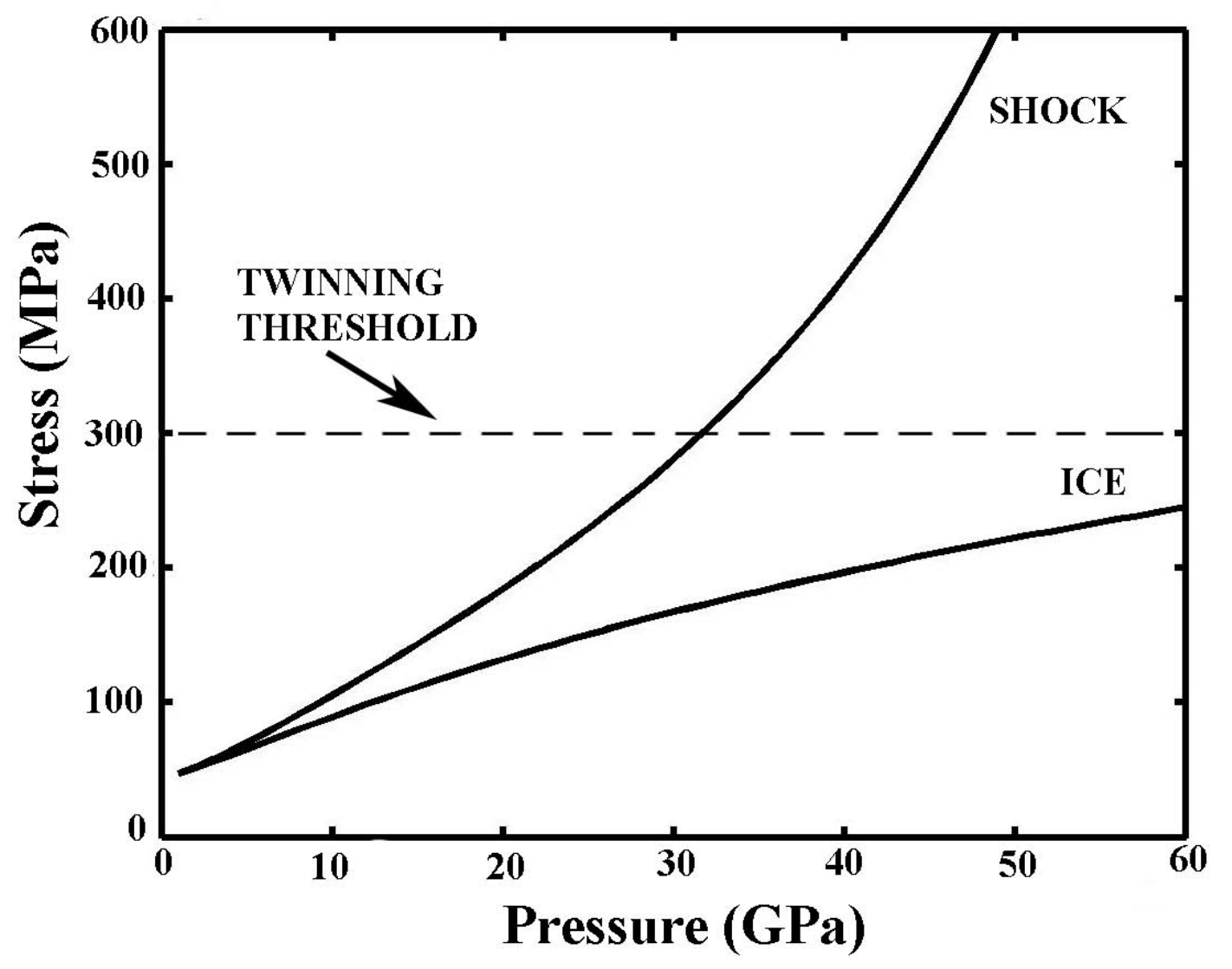

Figure 29: Z-A model showing pressure vs. flow stress of [001] copper in ICE and Shock 